\title{
Health, fitness, physical activity, and morbidity of middle aged male factory workers I
}

\author{
W TUXWORTH, ${ }^{1}$ A M NEVILL,${ }^{1}$ C WHITE, ${ }^{2}$ C JENKINS ${ }^{1}$ \\ From the Department of Physical Education and Sports Science, ${ }^{1}$ University of Birmingham, Birmingham \\ B15 2TT, and Cadbury-Schweppes plc, ${ }^{2}$ Bournville, Birmingham B30 $2 L U, U K$
}

\begin{abstract}
A description of the fitness, physical activity of lifestyle, and some aspects of health status and attitudes in a population of male factory workers aged 35-60 is presented as the first part of a report on a study of morbidity in this population. A total of 1394 subjects were included, undergoing medical examination, fitness testing by bicycle ergometry, assessment of body fat, and interview questionnaire. The inter-relation of fitness, body composition, habitual exertion, health risk factors, and attitudes to exercise are discussed. Fitness levels are compared with those reported in other studies and discussed in terms of capacity for walking and running and in relation to criteria for health benefit. In these two latter respects fitness appears to be inadequate among the great majority of those tested, although it is comparable with that reported by several other recent studies. Fitness is associated with physical activity of leisure but not that of work. Only relatively strenuous physical activity in leisure time appears to be related to fitness, and is only participated in by some $28 \%$ of the sample. Cycling has the strongest association with fitness of all the physical activity variables. Blood pressure and percentage body fat are also associated, inversely, with fitness, the latter not unexpectedly because of the weight related measure of fitness.
\end{abstract}

The relation between physical activity and health has been extensively studied over the past 30 years and comprehensively reviewed, ${ }^{1-7}$ interest focusing particularly on the possible significance of activity level in the aetiology of ischaemic heart disease (IHD). Despite the difficulty of using evidence of an epidemiological nature in establishing and verifying relations between different risk factors, a growing consensus of lay and medical opinion believes that physical activity may protect against heart disease. If so then its relative importance may well increase as the impact of other risk factors, particularly smoking, is reduced. A substantial decrease in incidence of fatal heart attacks in the United States has occurred recently alongside a major public response to specific health education programmes which have led to reduced smoking, modified diet, and increases in level and in incidence of exercise. It is not, however, possible to say which, if any, of these responses have been the effectors. If increased exercise has indeed contributed to the improved cardiac health of Americans further investigation will still be necessary to determine whether exercise is of direct benefit or whether its effect is to modify other risk factors, perhaps proAccepted 3 February 1986 moting greater tolerance, particularly of dietary factors. Encouraging evidence for this last explanation is accumulating from studies of serum lipids, ${ }^{89}$ especially when exercise is accompanied by weight loss.

Population studies of the relation between physical activity and incidence of IHD seldom include information about the physical condition of individuals, describing only physical activity and incidence of IHD. The present study including the direct assessment of fitness of individuals was undertaken for the following reasons.

(1) If increased physical activity is to be promoted as a health enhancing aspect of lifestyle, and given that fitness both aids and reflects that activity, it is necessary to know the present distribution and nature of both physical activity and fitness among the population expected to benefit from such an increase. No such information exists for Britain.

(2) The collection of such descriptive data in a substantial group of normal men in which morbidity and mortality can be monitored would in the long term help to clarify the inter-relation of physical fitness, activity, and health.

It was also considered that experience with exercise 
testing in a factory population would be of direct practical benefit to occupational medical professionals interested in fitness programmes.

A study with similar objectives examined the subsequent morbidity and mortality from IHD in Swedish men whose maximum oxygen uptake $\left(\dot{\mathrm{V}}_{2} \mathrm{max}\right)$ had been assessed at age $50{ }^{10} \mathrm{~A}$ questionnaire was also completed to ascertain physical activity of lifestyle as well as other health related behaviour such as smoking habits. Two features of the population tested cast doubt on the extent to which the findings of the study might be applicable to a similar population in Britain. One is the homogeneity of the sample in terms of $\dot{\mathrm{Vo}}_{2}$ max, only $1.5 \mathrm{ml} / \mathrm{kg} / \mathrm{min}$ separating the mean value for the group physically active at work and at leisure $(31.3 \mathrm{ml} / \mathrm{kg} / \mathrm{min})$ from that of the group sedentary in both $(29.8 \mathrm{ml} / \mathrm{kg} / \mathrm{min})$. The other is that the occupationally physically active men are heavier smokers. At the very least it was thought necessary to find out whether these two features might also be characteristic of a British population. Since the study began the results of another major study begun in 1971 have been published which show a predictive value for fitness testing on the occurrence of myocardial infarction. ${ }^{11}$

Also, since the study began in 1981, the design and methodology for a prospective epidemilogical study in Belgium has been published. ${ }^{12}$ This study had already begun in 1978 with the objective of examining the role of fitness and physical activity in the prediction of cardiovascular disease. A sample of 3179 men aged 40 to 55 was selected of whom $47.6 \%$ completed an exercise test. Cardiovascular morbidity is being monitored through notification of all 28 day absences from work or longer over a period of six years. Simultaneously with the announcement of the Belgian project, data were published describing the fitness and physical activity of the sample. ${ }^{13}$

\section{Procedures}

The measurement phase of the project necessitated a medical examination to establish health status, followed by physique assessment, measurement of cardiorespiratory work capacity using bicycle ergometry, and finally, the determination of physical activity of lifestyle by means of interview questionnaire.

The completion of this phase was to allow a descriptive picture to be drawn of the section of the population most at risk from heart disease, assuming, as seemed reasonable, that these workers were essentially typical of most of their age group in the population of England as a whole. The second phase (now in progress) requires the monitoring of morbidity in all included subjects for long enough to produce sufficient data to discern any relation between the ini- tial information gathered and subsequent morbidity. It was decided to attempt to monitor all illness resulting in at least four days absence from work rather than only diseases of a cardiovascular nature.

All men aged 35-60 at a food factory were asked to participate unless already known to have precluding medical conditions. Thus of an initial total nominal roll of 2142,82 were pronounced medically unfit, 83 left the factory (through early retirement, redundancy or other reasons) before they could be tested, and seven were lost owing to administrative error. Of the remaining 1977 potential subjects, 231 declined to participate, 345 failed to reply to the invitation, and $1394(70 \cdot 5 \%)$ completed all components of the investigation.

Of the 345 who failed to reply, many will have been non-responding decliners, but limited investigation also showed several people who claimed to have received no communication. It is not known to what extent this was a "polite" or embarrassed response to an unwelcome confrontation. It should also be noted that the voluntary nature of participation may well have led to a bias towards those who are fitter, more interested in physical activity, or more health conscious. There is no evidence that employees from any particular social class or type of job rejected the invitation. The whole range of grades of employee from cleaner to management is well represented.

Diminution in numbers through early retirement and redundancy was not envisaged when the project began in October 1979, the implications of the impending recession not being fully appreciated at that time. The poor economic climate also frustrated attempts to include at least one other factory in the study. The consequences of these factors for phase 2 of the study is that monitoring of as many as possible of the iniiial 1394 subjects will probably need to continue for more than the five years originally envisaged in order to assemble sufficient data. In addition, positive health education at the factory over several years seems to have borne fruit in the form of a reduction in recent incidence of coronary heart diseasehardly an unwelcome complication but one with obvious implications for the duration of the morbidity study. A "pruning" effect resulting from redundancies has also probably occurred.

\section{RECRUITMENT}

Every man aged between 35 and 60 on 1 October 1979 received a written invitation from the factory's medical department to join the project as a subject. The letter explained that the project was concerned with preventing heart disease and that involvement would include a non-exhausting exercise test preceded by a medical examination and an interview questionnaire. Positive respondents were then given an appointment 
for the medical and test procedures to be carried out within the participant's working time.

\section{Medical assessment}

Inevitably there are risks in performing exercise tolerance testing on a middle aged population. ${ }^{14}$ Steps were taken to minimise these risks while attempting to include the maximum possible number of subjects in the study. Medical records were available for most of the participants. These were updated by questionnaires and examination before the exercise test.

The medical questionnaire asked about previous significant medical history and current medication and treatment. Additional information on history of chest pain and exertional dyspnoea were obtained, together with a smoking history.

Each participant was examined by a physician immediately before testing. The medical records and the questionnaire were reviewed and any additional information recorded. The physical examination consisted of assessments of the heart, lungs, heart rate, and blood pressure. Quick checks were done to discover evidence of congestive cardiac failure and other systems requiring further examination were noted at this stage. A 12-lead resting electrocardiogram was then taken.

It was then decided whether to allow the subject to participate in the test. All subjects were clinically fit for work and in full time employment, total exclusion from the trial therefore being uncommon $(82,5 \cdot 5 \%)$. The contraindications followed were those outlined by the American Heart Association, ${ }^{15}$ and, in addition to cardiac criteria, included severe locomotive problems-for instance, multiple sclerosis, osteoarthritis of hips or knees, and intermittent claudication. Drug treatment may interfere with an exercise test and subjects taking beta-blocking agents and digitalis were therefore rejected. Those subjects with a history of myocardial infarction, angina, hypertension, and less severe intermittent claudication were tested with a physician familiar with exercise testing present in the laboratory during the test, the test being terminated prematurely if there was cause for concern. Although safety of the subjects was the paramount consideration, the availability of medical supervision permitted the inclusion of many people with serious clinical problems, minimising as far as possible any bias towards selection of the healthy.

\section{Exercise test}

The rationale for the selection of the exercise test mode, the design of the protocol, the nature of its administration, and the terms in which the physical fitness assessment is described are to be fully reported elsewhere. Briefly, it was decided to use a modification of submaximal bicycle ergometric pro- cedures to predict maximum oxygen consumption $\left(\dot{V}_{O_{2}} \max \right)$ (pioneered by Wahlung ${ }^{16}$ and Åstrand ${ }^{17}$ ) as being appropriate measures of cardiorespiratory functional capacity and yielding measures comparable with those from other recent studies. The protocol for this population was extensively piloted and modified to ensure appropriateness to the range of age and condition of the subjects.

In particular an attempt was made to ensure uniformity of relative exertion without exceeding recommended heart rate for a given age. ${ }^{18}$ Such procedures have also been adopted by the Council of Europe ${ }^{19}$ and the World Health Organisation. ${ }^{20}$

A "constant power" electrically braked bicycle was used to overcome any problems in controlling pedalling cadence. Chest electrodes and telemetry were used to portray heart rate and electrocardiogram (chest leads only). The use of telemetry was thought to avoid some subjects' apprehension at being connected to electrical instruments.

Because the subjects could not be habituated to the test, conditions were made as relaxed and informal as possible. All the subjects were familiar with having electrodes fixed to their chest, having just undergone a clinical electrocardiogram examination at the assessment medical. They also sat in the mobile unit answering the questions put to them about their lifestyle by friendly interviewers while watching the previous subject perform his bicycle test, usually enjoying it, and always surviving it. Administrators attempted to reassure subjects, but not excessively, about the non-exhausting nature of the test, and took particular care with those men who were clearly apprehensive or embarrassed about their condition. Some flexibility of appointment time was retained so that in certain cases rather more time could be made available for preparing or coaching or both of the subject.

A physician was on call at all times when testing took place. Full emergency equipment and drugs were available, including resuscitators and defibrilator. The company ambulance was on standby. The physician was present in the exercise laboratory during the testing of the special groups mentioned earlier and at all times could be called from his nearby office by a direct telephone or radio link.

\section{ANTHROPOMETRY}

Subjects were weighed on a Salter balance calibrated with standard weights and their height was recorded using a stadiometer. Wrist girth was measured using a non-stretch tape for an indication of skeletal bulk.

Body fat was assessed using the skinfold method and protocol of Durnin and Womersley - that is, the four skinfold sites designated as biceps, triceps, subscapular, and suprailiac. ${ }^{21}$ The four skinfold thick- 
nesses were summed and converted to estimated percentage body fat using the formula of Durnin and Womersley.

\section{Physical activity of lifestyle questionnaire}

In addition to the information sought as part of the medical examination a questionnaire was constructed that aimed to determine the physical activity of lifestyle of subjects and also to obtain some indication of attitudes to exercise and diet.

The questionnaire was administered by interview. This served the dual purpose of ensuring comprehension and consistency in interpretation of questions and that subjects were rested and relaxed before the exercise test. Every effort was made to ensure a friendly, informal atmosphere including the use of mature, female interviewers with sympathetic personalities.

Information about physical activity of lifestyle was sought in three areas; activity at work, activity at leisure, and disposition to exertion.

\section{Results}

The subjects were 1394 men aged between 35 and 60 who were representative of the occupational structure of the workforce. Just under $50 \%$ of the subjects were 50 and older.

\section{PHYSICAL CHARACTERISTICS}

The mean height for the whole sample is $176.46 \mathrm{~cm}$. Figure 1 shows that there is a statistically significant $(\mathrm{p}<0.001)$ monotonic decrease in height in relation to age. The difference in mean height between the oldest and youngest groups is $3.08 \mathrm{~cm}$ for the 20 years spanning the mean ages or about $1 \mathrm{~cm}$ for 6.5 years.

The mean gross body weight for the population is $76.84 \mathrm{~kg}(\mathrm{SD}=10.5)(\mathrm{fig} 2)$. There is no significant difference according to age.

Figure 3 shows the distribution of body mass index (Wt $(\mathrm{kg}) / \mathrm{ht}^{2}(\mathrm{~m})$ ) by age and according to Bray's classification for the assessment of relative overweight in terms of clinical criteria. ${ }^{22}$ Thus 720 subjects $(51.6 \%)$ are in the "acceptable" category, 596 $(42.8 \%)$ are overweight, and 78 are obese $(5.6 \%)$. Differences in body mass indices by age group are significant $(p=0.002)$.

Body fat, derived from skinfold measures and expressed as a percentage together with age, is shown in fig 4. Whereas there is no age related difference, in sum of skinfolds, Durnin and Womersley's conversion to percentage body fat takes account of their findings of higher percentage of fat for a given skinfold sum with increasing age. Thus percentage body fat increases significantly and progressively with age. Lean body mass as a percentage would be the residual

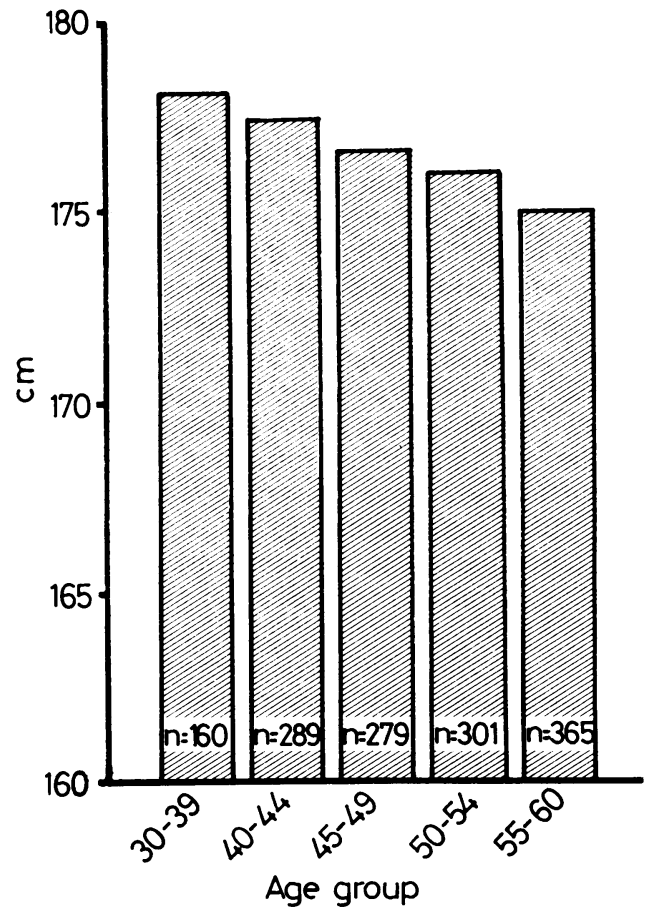

Fig 1 Mean height analysed by age.

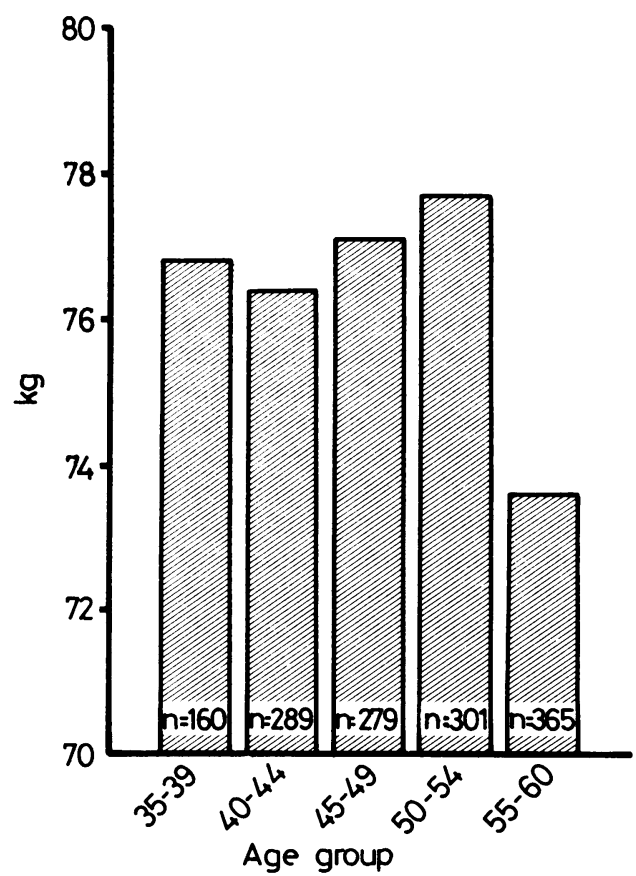

Fig 2 Mean weight analysed by age. 


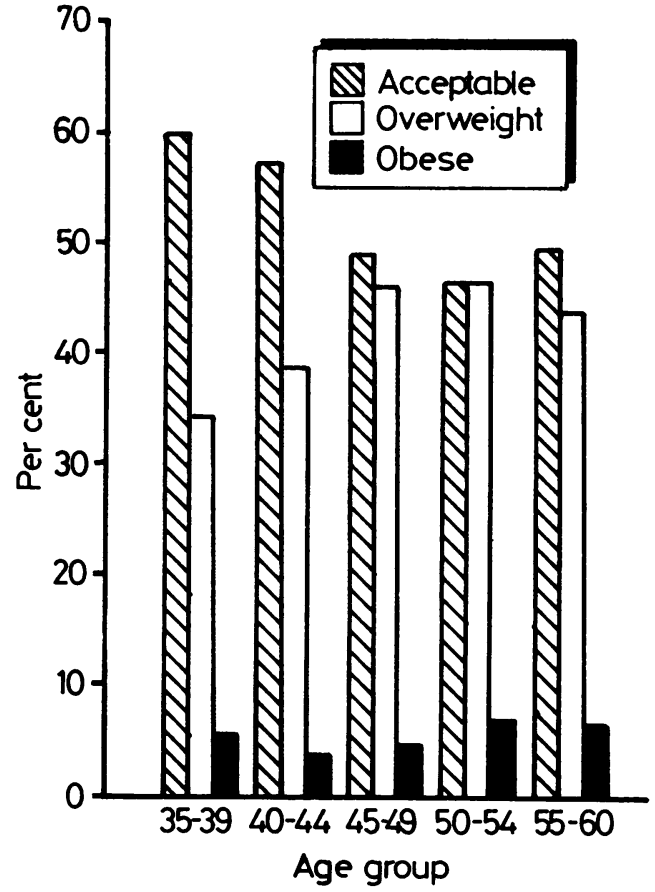

Fig 3 Body mass index distribution of categories (after Bray $^{22}$ ) by age.

of percentage body fat. With lean body mass expressed as an absolute value $(\mathrm{kg})$, however, body fat as a percentage increases in relation to lean body mass. Thus subjects with greater lean body mass tend to have relatively more body fat $(r=0.29$ after age correction).

The distribution of percentage of body fat over all ages shows $3 \cdot 1 \%$ to have below $15 \%$ body fat, $20 \cdot 1 \%$ to have $15-20 \%, 41 \%$ to have $20-25 \%, 29.6 \%$ to have $25-30 \%$, and $6 \cdot 2 \%$ to have over $30 \%$.

Although total skinfold thickness does not differ significantly with age, there is some age difference for individual skinfold measures. Skinfolds 1 and 2 (biceps and triceps) do not differ significantly with age, whereas skinfold 3 (subscapular) increases and skinfold 4 (suprailiac) decreases ( $p=0.007$ for both). Skinfold values for the different sites and wrist girth, both in relation to age, are shown in table 1A.

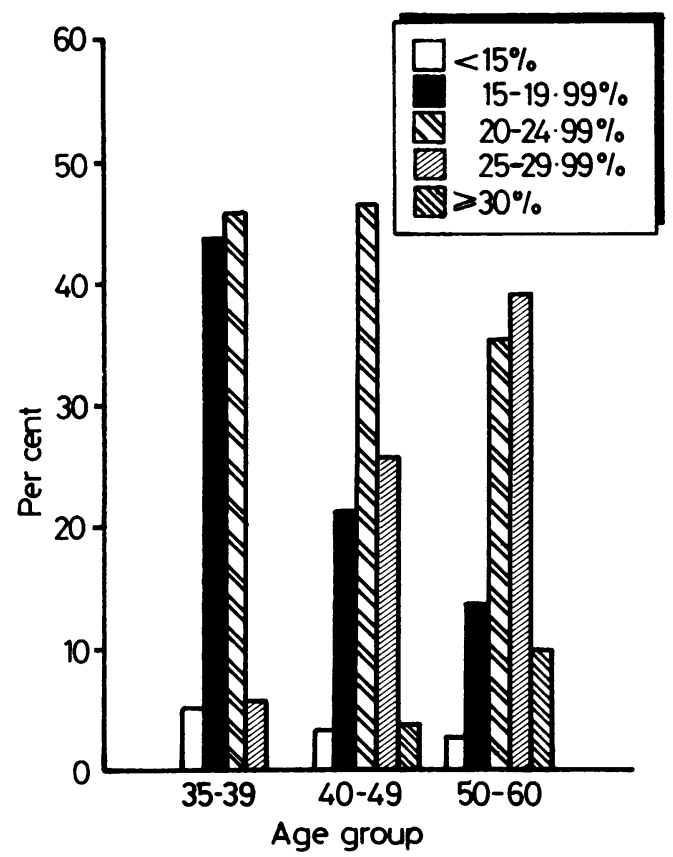

Fig 4 Distribution of body fat categories by age.

\section{MEDICAL STATUS}

The pretest medical interview showed histories of previous illness, case incidence being age related. Thus 102 were hypertensive $(7 \cdot 3 \%) ; 20$ had suffered myocardial infarction $(1.4 \%) ; 25$ had a history of angina pectoris $(1.8 \%)$; two had had a stroke, and 17 were diabetics $(1 \cdot 2 \%)$.

The incidence of previously diagnosed angina pectoris contrasts with the observation by 85 subjects at the medical that they experienced pain or discomfort when walking uphill or hurrying. Sixty four of these subjects reported having suffered severe pain lasting over one hour.

Over $20 \%$ of the sample indicated that they were either taking regular medication or following dietary constraints advised by a physician.

The electrocardiogram results were not included in the data analysis but used principally to assist in identifying subjects who would need direct supervision by

Table $1 \mathrm{~A}$ Skinfold values and wrist girth in relation to age

\begin{tabular}{|c|c|c|c|c|c|c|}
\hline Skinfold ( $\mathrm{mm}$ ) & $35-39$ & $40-44$ & $45-49$ & $50-54$ & $55-59$ & All \\
\hline $\begin{array}{l}\text { Biceps } \\
\text { Triceps } \\
\text { Subscapular } \\
\text { Suprailiac }\end{array}$ & $\begin{array}{r}4.69 \\
9.09 \\
15.00 \\
17.21\end{array}$ & $\begin{array}{r}5.00 \\
8.99 \\
14.85 \\
16.47\end{array}$ & $\begin{array}{r}5.00 \\
8.64 \\
15.94 \\
16.67\end{array}$ & $\begin{array}{r}5 \cdot 27 \\
9 \cdot 07 \\
16 \cdot 16 \\
15 \cdot 81\end{array}$ & $\begin{array}{r}5 \cdot 2 \\
9 \cdot 04 \\
16 \cdot 17 \\
15 \cdot 36\end{array}$ & $\begin{array}{r}5.07 \\
8.96 \\
15.71 \\
16.17\end{array}$ \\
\hline Wrist girth $(\mathrm{cm})$ & $18 \cdot 27$ & $18 \cdot 16$ & $18 \cdot 19$ & $18 \cdot 45$ & $18 \cdot 35$ & $18 \cdot 29$ \\
\hline
\end{tabular}




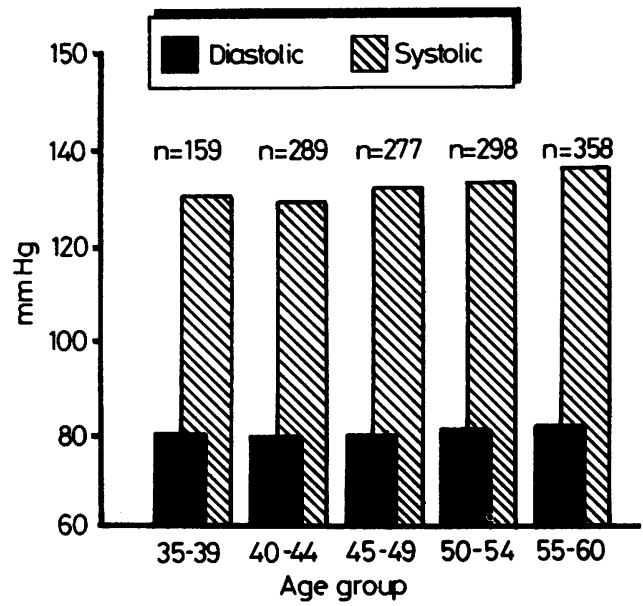

Fig 5 Mean blood pressure of different age groups.

a physician during the exercise test. Forty four were thus identified ( $3 \cdot 18 \%$ of the total sample).

Blood pressures recorded at the medical interview (fig 5) show an age related trend, greater for systolic than for diastolic pressure.

\section{PHYSICAL ACTIVITY LEVELS AT WORK AND LEISURE}

\section{Physical activity at work}

Ninety per cent of non-manual workers reported that they spent almost half of their working time sitting down compared with $10 \%$ of the manual workers. Self reported "walking about" during the working day followed the same pattern. Over $95 \%$ of the nonmanual workers compared with $55 \%$ of the manual workers did not exert themselves physically during the working day. Approximately $30 \%$ of the manual

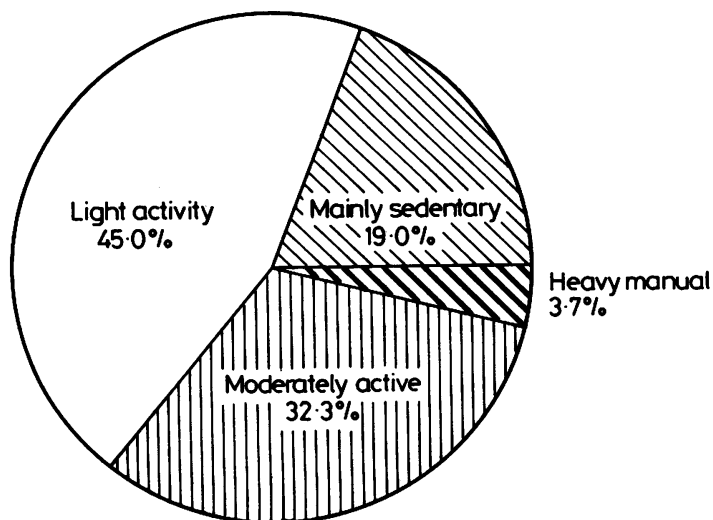

Fig 6 Self rated estimate of physical demands of work. workers claimed to lift objects of more than $20 \mathrm{lbs}$ $(10 \mathrm{~kg})$, or the eqivalent in terms of exertion, more than 20 times a day.

In response to being asked to describe their job in terms of its physical demands, $4 \%$ considered it exhausting with $32 \%$ judging their work to be strenuous. The remainder, $64 \%$, considered their job to be "light" or sedentary.

In an attempt to consolidate the picture of activity at work respondents were asked to identify with a general description of their job using four categories ranging from mainly sedentary to heavy manual. The responses are shown in fig 6 .

WALKING, INCLUDING TRAVEL TO WORK

Just over a third of the respondents claimed to walk on average for more than five hours a week whereas $25 \%$ walked for less than two hours a week.

PHYSICAL ACTIVITY DURING LEISURE TIME

Three generalised levels of exertion were identified. The first comprised activities requiring "fairly light" physical exertion such as bowling, fishing, and gardening (assuming little heavy digging and the use of, for instance, a powered mower). The second, identified as "fairly strenuous," included jogging, swimming, and badminton. The third level described as "relatively exhausting or played competitively or both," included squash, football, cycling as a sport, and running.

Figure 7 shows the participation in the fairly lighto category, nearly half the subjects spending at least five? hours a week in this way.

Twenty eight per cent of the respondents claimed to take part in more strenuous activities such as jogging and badminton (fig 8).

Only a small minority of the respondents, $6 \%$,

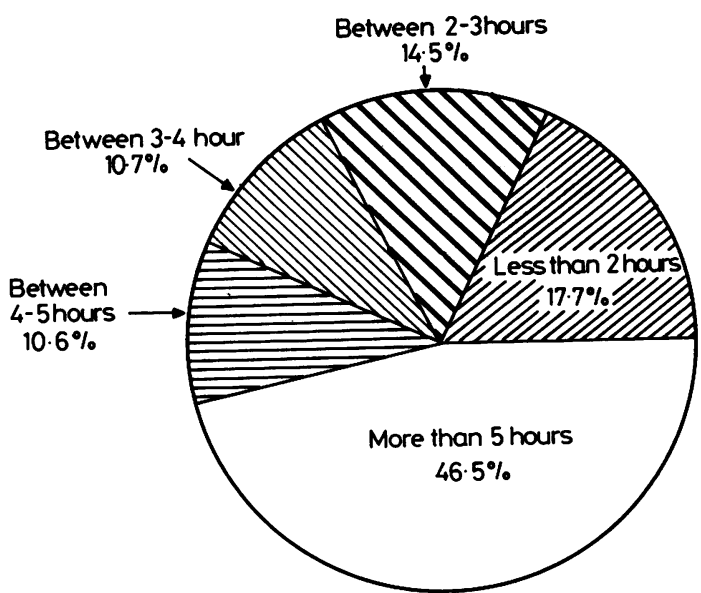

Fig 7 Hours spent each week on "fairly light" activities. 
engaged in relatively exhausting physical activities and participation decreased with age (fig 9).

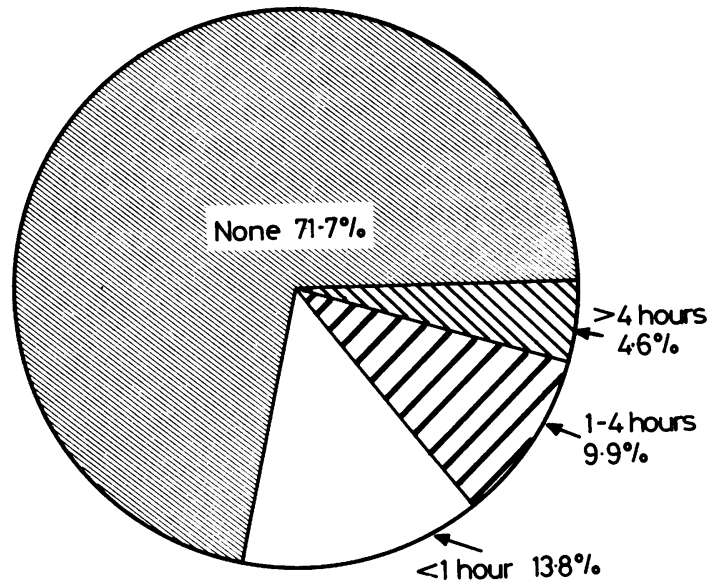

Fig 8 Hours spent each week on relatively strenuous physical activities.

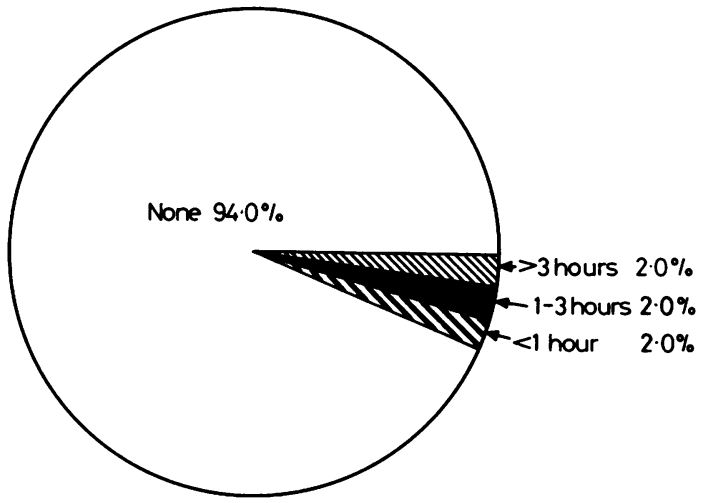

Fig 9 Hours spent each week on relatively exhausting physical activities.

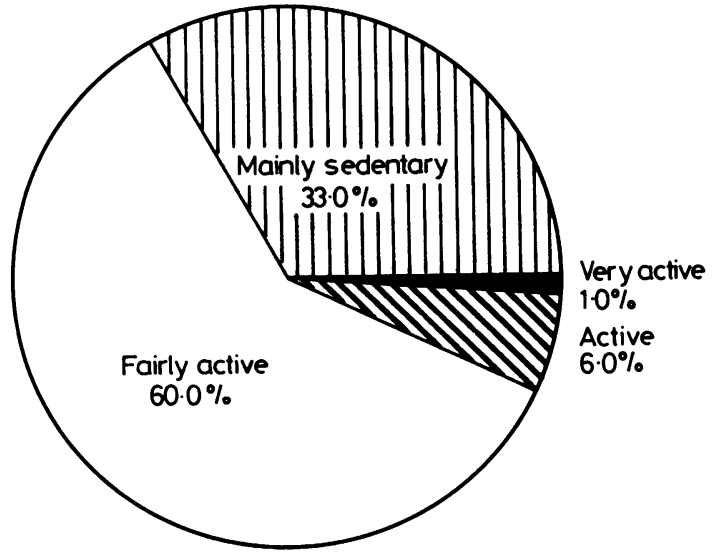

Fig 10 Perceived activity levels.
To reinforce the replies to questions on physical activity respondents were asked to give a self rated assessment of their perceived activity level at leisure (fig 10). Almost two thirds perceived themselves as "fairly active."

\section{GENERAL LIFESTYLE ACTIVITY}

In addition to questions designed to obtain information on quantifiable activity levels at work and in leisure time, an attempt was made to elicit some indication of predisposition to exertion via two questions which approached this attribute indirectly. The first of these asked respondents, "If the occasion were to arise, would you run in order to catch a bus or if late for an appointment?" One third of the respondents replied that they would rarely or never run for a bus, $37 \%$ replied sometimes, and $30 \%$ stated that they would run for a bus. The second question asked "Do you run up stairs?" Just under one third of the sample claimed that they often ran up stairs, $31 \%$ sometimes, and $41 \%$ rarely or never.

\section{ATTITUDES TO EXERCISE AND DIET}

Over $95 \%$ of the respondents thought that exercise was certainly "good for health," just under $4 \%$ were uncertain, and only $1 \%$ (15 respondents) considered that exercise was either "unlikely to be good for health" (10) or definitely "not good for health" (5).

Over $80 \%$ considered that exercise was of some value in weight control. Forty six per cent tried to limit their intake of food, $27 \%$ "regularly" and $19 \%$ "sometimes." Sixty four per cent made conscious attempts to cut out completely or to eat less of particular foods. Thus $34 \%$ of the respondents deliberately limited their use of sugar, with $43 \%$ controlling their intake of fats and $23 \%$ their intake of starches. Over $50 \%$ reported that they tried to limit their consumption of animal fats and $7 \%$ cut out animal fats entirely.

\section{SMOKING HABITS}

Respondents were questioned in some detail about their present and past smoking habits. The results were analysed by age group to allow comparisons to be made with data on cigarette smoking produced by the General Household Survey (GHS) published in $1983^{23}$ (table 1).

Table 1 Respondents' smoking habits analysed by age (\%). ( $\%$ in parentheses from General Household Survey) $)^{\mathbf{2 3}}$

\begin{tabular}{|c|c|c|c|c|}
\hline \multirow[b]{2}{*}{$\begin{array}{l}\text { Age } \\
\text { group }\end{array}$} & \multirow[b]{2}{*}{ No } & \multirow[b]{2}{*}{$\begin{array}{l}\text { Current } \\
\text { smokers } \\
\%(\%)\end{array}$} & \multicolumn{2}{|c|}{ Current non-smokers } \\
\hline & & & $\begin{array}{l}\text { Ex-regular } \\
\text { smokers } \\
\%(\%)\end{array}$ & $\begin{array}{l}\text { Never or } \\
\text { occasionally } \\
\%(\%)\end{array}$ \\
\hline $\begin{array}{l}35-49 \\
50-59\end{array}$ & $\begin{array}{l}727 \\
633\end{array}$ & $\begin{array}{l}33.8(40) \\
34.9(42)\end{array}$ & $\begin{array}{l}28 \cdot 3(32) \\
45 \cdot 7(38)\end{array}$ & $\begin{array}{l}37.8(28) \\
19 \cdot 4(20)\end{array}$ \\
\hline
\end{tabular}


About one third of the respondents in each of the age groups 35-49 and 50-59 were current smokers ( $40 \%$ and $42 \%$ respectively in the GHS sample).

Of those in the 35-49 age group, $28 \%$ were exregular cigarette smokers, having now given up the habit (32\% in the GHS sample). In the 50-59 age group $46 \%$ of the factory respondents had stopped smoking compared with $38 \%$ of the GHS sample.

Thirty eight per cent of the factory respondents had never smoked compared with $28 \%$ of the GHS sample who had never or only occasionally smoked.

These data closely reflect the general pattern of the results of the GHS except that the factory data show a somewhat smaller percentage of workers to be smoking than is the average nationally, with a larger percentage of the workers having given up smoking than has occurred nationally.

Mean body weight analysed by smoking habits and age shows the smokers to be generally lighter (mean weight $75.0 \mathrm{~kg}$ ) than those who have never smoked $(77.41 \mathrm{~kg})$. Ex-smokers are the heaviest group $(78.11 \mathrm{~kg})$. These differences are significant $(p<$ 0.0001 ) and occur at all ages except in the age group 40-44 when those who have never smoked are the heaviest group.

FITNESS DATA

Fitness, expressed as gross and weight related esti-

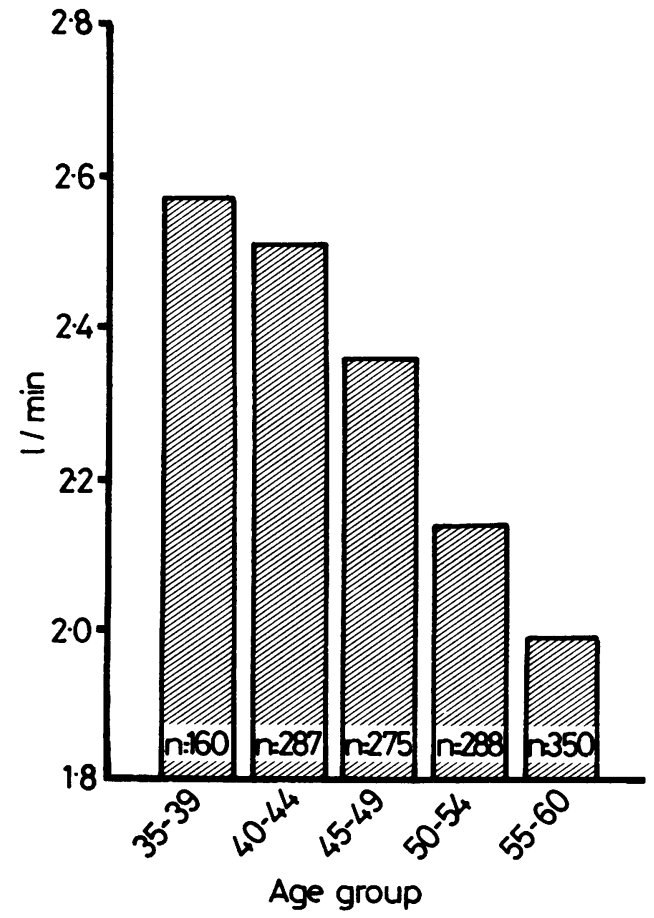

Fig 11 Gross fitness scores, $\dot{V}_{2}$ max, by age. mated $\dot{\mathrm{V}}_{2}$ max, shows a clear age related trend, the observed gross values being $0.581 / \mathrm{min}$ less $(-22.57 \%)$ for the oldest group than for the youngest. These data are shown in fig 11 . The mean value for gross $\dot{V O}_{2} \max$ is $2 \cdot 21 / \mathrm{min}$.

The effect of body weight in producing these differences in fitness according to age is of little consequence, the equivalent weight related values (fig 12) being $7.47 \mathrm{ml} / \mathrm{kg} / \mathrm{min}$ less (or $-22 \cdot 15 \%$ ). The effect of

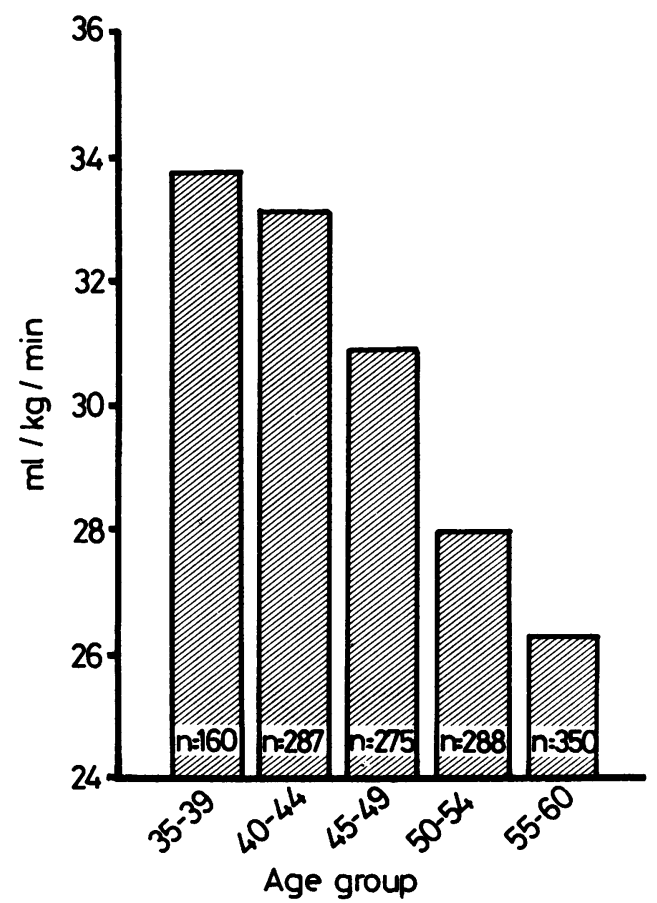

Fig 12 Weight related fitness scores, $\dot{V} \mathrm{o}_{2} \max / \mathrm{kg}$, by age.

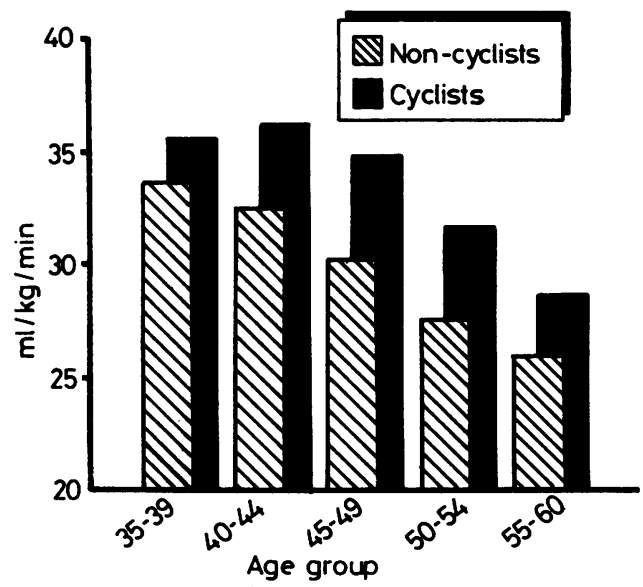

Fig 13 Fitness scores, $\dot{V} o_{2}$ max $/ \mathrm{kg}$, of cyclists compared with non-cyclists. 
age appears to increase after 45 . Mean weight related $\grave{\mathrm{V}}_{2} \mathrm{max}$ is $29.88 \mathrm{ml} / \mathrm{kg} / \mathrm{min}$. Age differences for both measures of fitness are significant $(p=0.001)$

\section{CYCLING AND FITNESS}

A total of 189 respondents claimed to ride a bicycle. The mean weight related $\dot{\mathrm{Vo}}_{2} \max$ for this group is $33.6 \mathrm{ml} / \mathrm{kg} / \mathrm{min}$ compared with 29.32 for the remainder (1169) of the sample. This fitness advantage (about 12\%) for the cyclists compared with those who do not cycle is found in each of the age groups (fig 13).

\section{PARTICIPATION IN RELATIVELY STRENUOUS}

ACTIVITIES

Fitness measures of the sample were analysed by the number of hours of participation each week in relatively strenuous physical activities. The results are shown in fig 14.

\section{PARTICIPATION IN RELATIVELY EXHAUSTING} ACTIVITIES

Fitness measures of the sample were analysed by the number of hours of participation each week in relatively exhausting physical activities. The results are shown in fig 15.

\section{GENERAL LIFESTYLE ACTIVITY AND FITNESS}

Fitness measures of the sample were analysed by the response to the questions "would you run up stairs?" and "would you run for a bus?" for each of the age groups. The results are shown in fig 16 and 17 respectively.

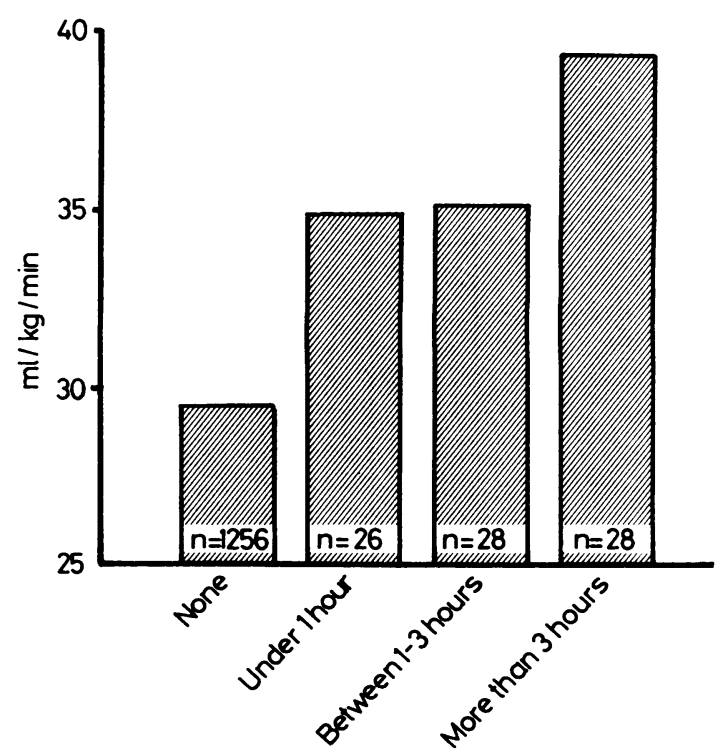

Fig 14 Fitness scores, $\dot{V} o_{2} \max / k g$, analysed by relatively strenuous physical activity per week.
Cross tabulation of the responses to these two questions showed a significant relation $(p<0.001)$. Despite this strong tendency for those people who were inclined to run up stairs to also run for a bus, however, the same consistency of behaviour was not shown in all subjects. Thus 188 respondents either never ran up stairs while always running to catch a bus or vice versa.

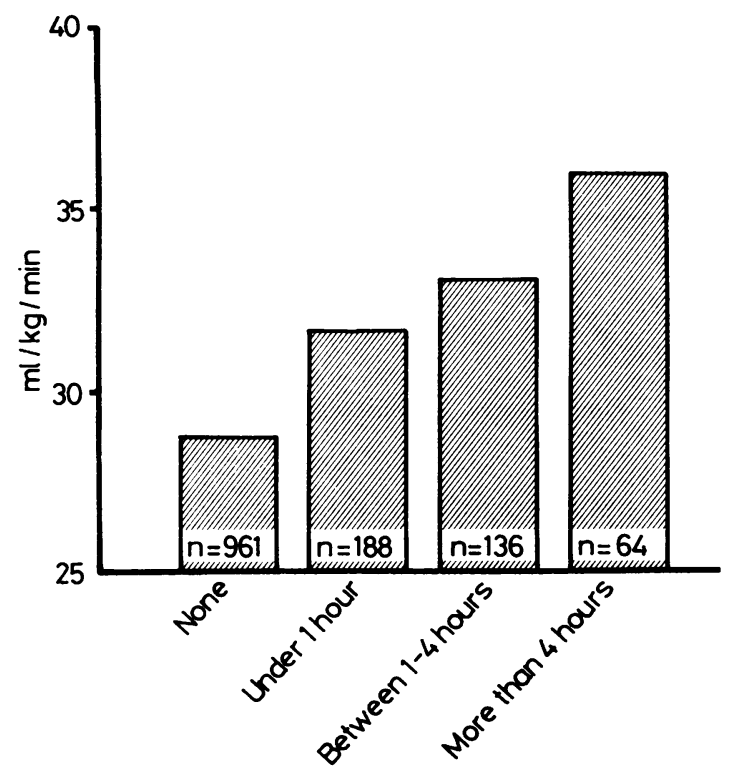

Fig 15 Fitness scores, $\dot{V} o_{2} \max / \mathrm{kg}$, analysed by relatively exhausting physical activity per week.

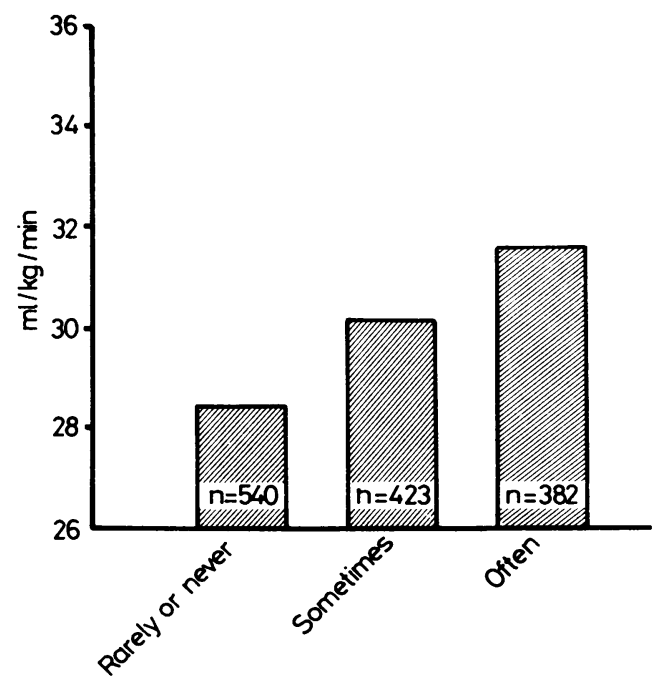

Fig 16 Fitness scores, $\dot{V} o_{2}$ max $/ k g$, analysed by "run up stairs." 


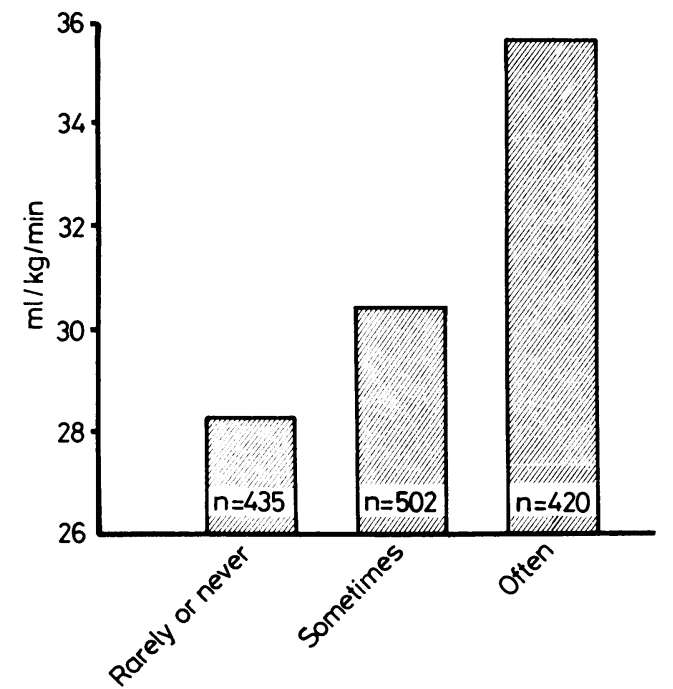

Fig 17 Fitness scores, $\dot{V} o_{2}$ max $/ k g$, analysed by "run for a bus."

SELF REPORTED ACTIVITY LEVEL

Weight related $\dot{\mathrm{V}}_{2}$ max values according to self reported activity levels (fig 18) differ significantly.

\section{SELF RATED ESTIMATES OF FITNESS}

Weight related $\dot{V}_{o_{2}} \max$ values differ significantly ( $p=<0.001$ ) according to self rated estimates of fitness. This difference persists in all age groups (fig 19).

\section{SMOKING HABITS AND FITNESS}

Figures 20 and 21 show the relation between fitness and smoking habits. Differences are not significant ( $p$ $=0.202$ and 0.16 for gross and weight related fitness).

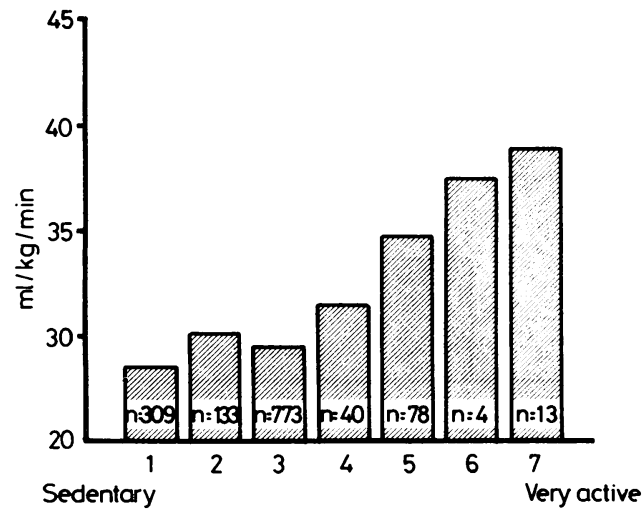

Fig 18 Fitness scores, $\dot{V}_{2} \max / \mathrm{kg}$, analysed by self reported activity levels.
MULTIPLE REGRESSION ANALYSIS

Multiple regression techniques were used to select and combine those independent variables which in this population have the greatest predictive power in relation to the dependent variable, fitness.

Table 2 shows the results produced by this analysis.

Hence, given an individual's scores on the ten variables, using the above model, it is possible to predict their fitness score with a standard error equal to $6 \cdot 1 \mathrm{ml} / \mathrm{kg} / \mathrm{min}$.

\section{Discussion}

PHYSIQUE AND BODY COMPOSITION

The differences in height between the age groups may

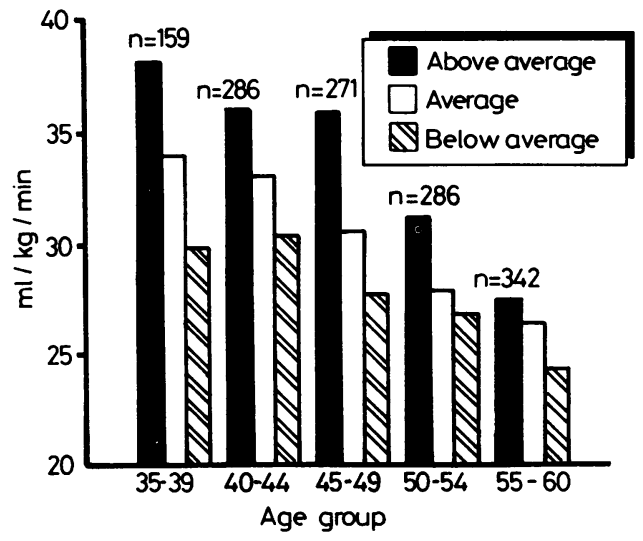

Fig 19 Fitness scores, $\dot{V} o_{2} \max / \mathrm{kg}$, analysed by solf rated estimate of fitness and age group.

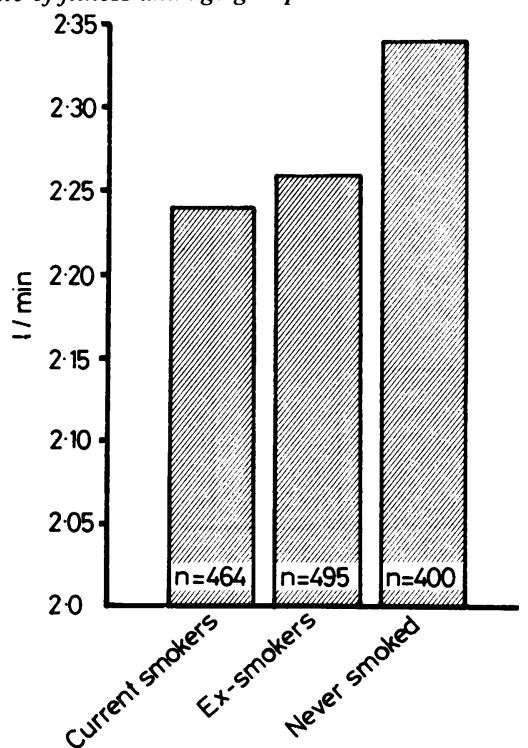

Fig 20 Fitness scores, $\dot{V}_{2}$ max analysed by smoking habits. 


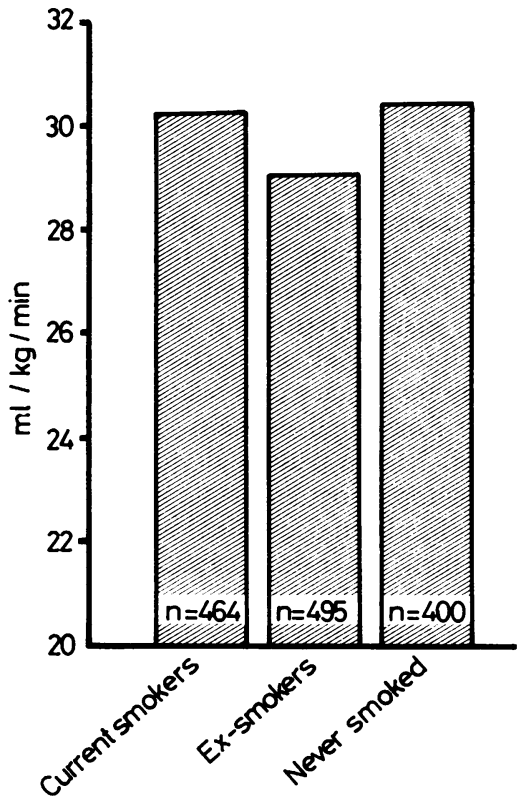

Fig 21 Fitness scores, $\dot{V} o_{2} \max / k g$, analysed by smoking habits.

represent an age related decline or merely reflect the increase in male adult height that has occurred over the past two decades or, indeed, both.

Table 2 Variables associated with fitness selected by the multiple regression analysis

\begin{tabular}{lll}
\hline Variables & $B_{\mathrm{i}}$ & $\begin{array}{l}\text { Beta } \\
\text { coefficients }\end{array}$ \\
\hline 1 Age & -0.26 & -0.24 \\
2 Percentage body fat & -0.31 & -0.18 \\
3 Systolic blood pressure & -0.07 & -0.12 \\
4 Cycling & +1.12 & +0.15 \\
5 Participation in relatively & +1.56 & +0.11 \\
$\quad$ exhausting sports & -0.41 & -0.16 \\
6 Body mass index & +0.57 & +0.06 \\
7 Would you run for a bus? & -0.05 & -0.07 \\
9 Diastolic blood pressure & & +0.07 \\
$\quad$ strenuous activity & +0.65 & +0.07 \\
10 Wrist girth & +1.14 & \\
11 Constant (A) & 60.1 & \\
\hline
\end{tabular}

Multiple $\mathbf{R}=0.59$.
The lack of significant age related trend in body weight and body mass index was not expected, in that population surveys commonly show increases in these closely related parameters with age. The Canadian Employee Fitness Survey ${ }^{24}$ data are comparable with our results for the age range surveyed (table $2 \mathrm{~A}$ ) in that weight appears to change little during middle age, the increase occurring principally during early manhood. It will be noticed that whereas both height and weight are similar to that of the factory population, body fat is somewhat greater for the Canadians of equivalent age.

Body mass index is widely used as an indicator of overweight and obesity. Using Bray's nomogram, ${ }^{22}$ values below $24.5\left(\mathrm{wt} / \mathrm{ht}^{2}\right)$ are "acceptable," between 24.5 and 29.5 are "overweight," and above 29.5 are "obese." By this classification the distribution of the factory workers is shown in fig 3 .

Body mass index is an incomplete and sometimes incorrect indicator of relative fatness because it fails to discriminate between skeletal and muscle bulk and fat. Body density is a useful measure to achieve this discrimination but was not available to this study. Percentage body fat, however, was assessed, and it is interesting to see how the distribution of the population by body fat criteria-that is, skinfold measures - compares with distribution by body mass index.

Taking $50 \mathrm{~mm}$ total skinfold as an arbitrary threshold, above which men might be considered to be overweight or obese (representing $21.5 \%, 24.6 \%$, and $26.4 \%$ fat for the three age groups by decade), 491 men have over $50 \mathrm{~mm}$ total skinfold, 94 of whom are in the acceptable category by body mass index. By contrast, 12 of those classified as obese have less than $50 \mathrm{~mm}$ total skinfold. The wrist girth of these 12 subjects $(19.37 \mathrm{~cm})$ shows them to be individuals of well above average skeletal bulk (mean wrist girth = $18.29 \mathrm{~cm}$ ) almost certainly accompanied by a tendency to mesomorphy. Wrist girth of the 94 subjects classified as acceptable despite more than $50 \mathrm{~mm}$ total skinfold, however, is less than average $(17.8 \mathrm{~cm})$, showing them to be small boned individuals of endomorphic tendency. All these subjects are miscast in terms of relative adiposity by the criterion of body mass index.

Table 2A Mean height, weight, and percentage body fat of Canadian employees

\begin{tabular}{|c|c|c|c|c|c|}
\hline & \multicolumn{5}{|c|}{ Ages (years) } \\
\hline & $17-19$ & $20-29$ & $30-39$ & $40-49$ & $50-59$ \\
\hline $\begin{array}{l}\mathrm{Ht}(\mathrm{cm}) \\
\mathrm{Wt}(\mathrm{kg}) \\
\mathrm{Wt} / \mathrm{ht}^{2}\left(\mathrm{~kg} \cdot \mathrm{m}^{-2}\right) \\
\text { Body fat }(\%)\end{array}$ & $\begin{array}{l}176 \cdot 8 \\
71 \cdot 2 \\
22 \cdot 78 \\
17 \cdot 7\end{array}$ & $\begin{array}{c}176 \cdot 3 \\
74 \cdot 0 \\
23 \cdot 91 \\
20 \cdot 2\end{array}$ & $\begin{array}{c}176 \cdot 3 \\
77 \cdot 1 \\
24 \cdot 81 \\
21 \cdot 9\end{array}$ & $\begin{array}{c}175 \cdot 5 \\
77 \cdot 6 \\
25 \cdot 19 \\
22 \cdot 8\end{array}$ & $\begin{array}{c}174 \cdot 1 \\
76 \cdot 5 \\
25 \cdot 23 \\
23 \cdot 5\end{array}$ \\
\hline
\end{tabular}


Among the overweight, with an excess body fat representing several per cent of body weight, weight related fitness would be substantially improved by weight reduction alone. The loss of body fat would also bring considerable health benefits besides those associated with improved fitness, relative obesity being a contributory or associated condition in a large range of serious disease syndromes. ${ }^{25}$

In addition to body fat as a percentage being significantly greater for older men, the distribution as indicated by individual skinfold thickness shows an interesting trend. Whereas biceps and triceps skinfolds are the same at all ages, the subscapular skinfold increases with age by the order of $8 \%$, while suprailiac skinfold decreases by a somewhat greater amount, $10.74 \%(\mathrm{p}=0.01$ in both cases $)$.

As with all other parameters, the levels and distribution among the subjects described, recruited as they were on a voluntary basis, may not comprehensively represent the population as a whole, particularly in certain respects. Thus the apparent homogeneity of body weight according to age may to some extent reflect a tendency for the overweight and obese to decline to participate in the study.

\section{FITNESS}

\section{Interpretation of recorded levels}

The measure of fitness is somewhat difficult to interpret unless some reference is made to population norms, to the levels of fitness considered necessary for health, or to the practical implications of the measure in terms of the requirements of familiar everyday tasks or sporting activity.

\section{ENERGY COST OF NORMAL ACTIVITY}

Perhaps it will be most useful to start by quantifying the energy expenditure requirements of normal activity. If such activity is to be performed continuouslythat is, without rapid exhaustion-then aerobic resources must be adequate to enable the task to be achieved in "steady state." Maximum steady state work is of the order of $60 \%$ of the $\dot{V}_{2} \max$ for untrained middle aged individuals, in comparison
Tuxworth, Nevill, White, Jenkins $\stackrel{\frac{\omega}{c}}{c}$ with more than $80 \%$ for an elite marathon runner. Soㅡㅡㄹ not only is $\mathrm{VO}_{2}$ max itself lower in untrained and这 older people but the percentage of that $\dot{\mathrm{V}}_{2} \max$. available for continuous work is also lower.

The biological principle that underlies the rationale for training is that the body adapts to maintain $\mathrm{a}_{\bar{C}}$ functional reserve capacity above the habitual $\overline{\bar{c}}$ demand. Thus training both increases maximum $\vec{\nabla}$ capacity and makes a given level of submaximal work $\varrho$ progressively easier. Detraining, or progressive reduction of the habit level of exertion, has the reverse $\vec{O}$ effect, maximal capacity decreasing to preserve only the required functional capacity above the reduced $\vec{\omega}$ activity level. It is not difficult to understand how individuals whose most energetic regular activity for $\frac{\mathbb{D}}{3}$ several years has been occasional walking may in theory reduce their maximum capacity to little above $\omega$ that which walking demands.

The energy needs of walking and running are pro- $\omega$ portional to body weight and speed. Different studies $\omega$

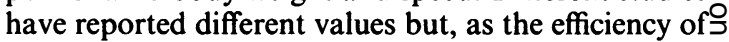
muscular activity varies little with a familiar and sim- ple action, these differences are small. Thus walkingo on the level at a normal pace of say $5 \mathrm{~km}$ an hour, will require about $15 \mathrm{ml}$ of oxygen to be used per kilogram

Table 3 Energy cost of walking and running at various speeds for an individual weighing $76 \mathrm{~kg}$ (based on Van derWalt and Wyndham ${ }^{26}$ )

\begin{tabular}{|c|c|c|}
\hline$(\mathrm{km} / \mathrm{h})$ & $\dot{V}_{\mathrm{O}_{2}}(\mathrm{ml} / \mathrm{kg} / \mathrm{min})$ & $\begin{array}{l}\dot{V} \mathrm{O}_{2} \text { max for steady } \\
\text { state performance* }\end{array}$ \\
\hline \multicolumn{3}{|l|}{ Walking: } \\
\hline 5 & $15 \cdot 14$ & $25 \cdot 23$ \\
\hline 6 & $19 \cdot 17$ & 31.95 \\
\hline 7 & 23.92 & $39 \cdot 87$ \\
\hline \multicolumn{3}{|l|}{ Running: } \\
\hline 8 & $34 \cdot 54$ & $57 \cdot 56(43 \cdot 18)$ \\
\hline 9 & $36 \cdot 53$ & $60.88(45.66)$ \\
\hline 10 & 39.61 & NA $(49 \cdot 51)$ \\
\hline 11 & $41 \cdot 21$ & NA $(51 \cdot 51)$ \\
\hline
\end{tabular}

*Assuming maximum steady state capacity to be $60 \%$ of $\dot{\mathrm{V}}_{2}$ max. Figures in parentheses assume $80 \%$-that is, trained individual $\mathrm{Vo}_{2}$ max values above $60.88 \mathrm{ml} / \mathrm{kg} / \mathrm{min}$ are not given at the $60 \%$ leve as they are unlikely to occur in untrained individuals.

Table 4 Numbers (percentages) of subjects' with different levels of fitness: distribution by age

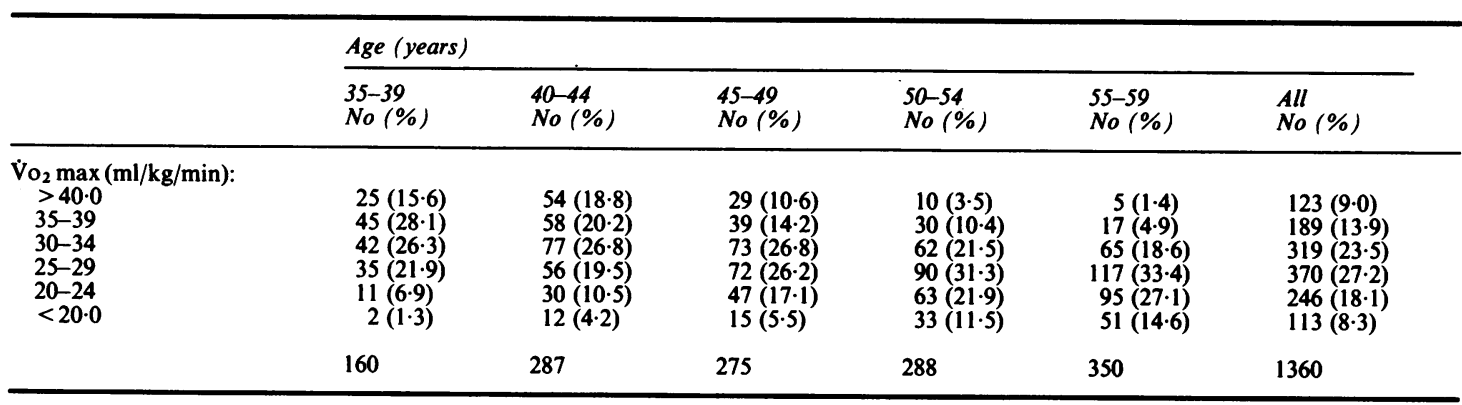


of body weight per minute $(1 \cdot 141$ a minute for the $76 \mathrm{~kg}$ mean weight of the population described).

Table 3 gives equivalent $\dot{\mathrm{Vo}}_{2}$ values for different speeds of running and walking according to Van der Walt and Wyndham ${ }^{26}$ whose prediction equations for energy cost of locomotion in the experience of these authors consistently produce values close to those achieved by laboratory measurement.

An examination of the distribution of fitness levels (table 4), together with reference to the values for walking and running, will clarify the capacity of the population to carry out these basic physical tasks.

Any level of exertion above maximum "steady state" capacity will bring rapid exhaustion if performed continuously because of its dependence on a component of anaerobic energy resources. Thus only $15.6 \%$ of 35-39 year olds are capable of sustained continuous running even at minimal jogging speed and only $1.4 \%$ of those aged 55-59. Capacities are clearly related to normal maximal habitual levels of exertion, in most cases walking, and in many cases walking slowly.

The term "continuous" begs the question to some extent regarding the practical ability of people to exert themselves above steady state levels. All short term high energy output activities are performed anaerobically - that is, actions such as jumping and sprinting. But such anaerobic resouces are limited and can only sustain activity for a few seconds at most. Used in conjunction with aerobic resources they can allow the performance of above steady state activity for a duration in inverse proportion to their contribution.

But anaerobic resources also tend to be much lower in people unused to vigorous exercise. Thus for someone whose maximum steady state capacity is, say, walking at $6 \mathrm{~km}$ an hour, to increase that speed to a brisk walk or jog, or to walk at the same speed up a gentle slope or against a stiff breeze, will bring about the need for an anaerobic contribution to the energy cost of exertion. Very soon he will be forced to slow down or rest as the lactate penalty for anaerobic activity accumulates. Such an individual is quite typical of this population-near the mean fitness value for the entire age range, with $75 \%$ of the men aged 55 or more being below this level. For all these people, running at any pace, stair climbing, and all similar exertion is short term exhausting work.

A further dimension to this situation is the subjective response to exertion of this nature. It is a frequent observation that those least used to strenuous exercise find it most uncomfortable. Among such individuals, particularly if they are overweight, body temperature will rise to a higher level and more quickly for a given rate of exertion, heat loss mechanisms being untrained and frustrated by relatively small surface area to volume and a tendency for the sedentary person to wear rather more clothing than the habitually active person. The respiratory response to exercise as well as heart rate will be accelerated by the thermoregulatory distress, all of which the individual will find disagreeable and, because it is unfamiliar, alarming. This subjective response will reinforce the avoidance of exertion.

\section{THRESHOLDS OF PROTECTION FROM}

\section{CARDIOVASCULAR DISEASE}

Whereas many studies have shown that a lower incidence of coronary heart disease occurs among physically active individuals, few studies have identified or quantified the nature and amount of exercise needed for such protection. A study to show a relation of morbidity to lifestyle needs to involve such large numbers that fitness evaluation of individuals and detailed monitoring of lifestyle is usually impossible. Nevertheless, two major contributions have been made in this respect, notably by Paffenbarger ${ }^{27}$ and Morris. ${ }^{28}$ The former, in the well known study of Californian longshoremen, a 22 year monitoring of nearly 4000 men, shows that protection seems to be afforded by occupational activity exceeding $8500 \mathrm{kcal}$ a week. ${ }^{27}$ For this to be achieved in a 37 hour working week, a mean rate of just under $4 \mathrm{kcal}$ a minute would be necessary-about $10 \mathrm{ml}$ oxygen $/ \mathrm{kg} / \mathrm{min}$. This appears reassuring, being well within the steady state capability of most of the population described. When looked at realistically, however, this would represent continuous very slow walking, an unlikely pattern of dockland activity. Much more probable is that the overall exertion is made up of substantial periods of low activity, sitting, and resting; periods of moderate exertion; and frequent bouts of strenuous effort. Paffenbarger draws attention to this latter point.

This leads to the consideration that the intensity and frequency of moderate or strenuous work may be of greater consequence than total energy expenditure. Morris's study strongly supports this, with the finding that, in an 8.5 year morbidity monitoring of nearly 18000 civil servants, those reporting vigorous leisure time activity had an incidence of coronary heart disease less than half that suffered by those not reporting such activity. ${ }^{28}$ Moreover, Morris succeeded, albeit approximately, in identifying a threshold of protection, quantifying vigorous exercise as that requiring more than $7.5 \mathrm{kcal} / \mathrm{min}$. This figure, taken from the classification of energy expenditure of Passmore and Durnin ${ }^{29}$ is equivalent to a gross $\dot{\mathrm{V}}_{2}$ of about $1.51 / \mathrm{min}$ or, for the mean body weight of the factory population, about $20 \mathrm{ml} / \mathrm{kg} / \mathrm{min}$.

It will be seen that this level of activity is beyond the steady state capability of most of the population described, assuming that this would imply a $\mathrm{Vo}_{2} \max$ 
of at least $33 \mathrm{ml} / \mathrm{kg} / \mathrm{min}$. It might be argued that activity of the required threshold level does not necessarily have to be performed in a steady state. Nevertheless, habitual involvement in such exertion could be expected to have brought about a functional reserve capacity well beyond the needs of that exertion. In other words the low capacities of the population are strongly indicative of a correspondingly low habitual intensity of exercise.

A further study by Paffenbarger of deaths from coronary heart disease and other causes among college allumni showed that those with a total leisure time energy expenditure during exercise and habitual general exertion exceeding $2000 \mathrm{kcal}$ a week were at $39 \%$ less risk of coronary heart disease than men expending less than 2000 kcals. $^{30}$ A small difference, again in favour of the more energetic group, was observed in death rates from other causes. An interesting feature of this study was that exercise habits as a young man afforded no protection in later life. The only effective exercise pattern was one sustained through the later years.

Finally, the study by Peters et al of myocardial infarction (MI) in relation to measured fitness in a five year follow up study of 2779 firemen and policemen reports over twice the incidence of MI among those subjects with less than the mean level of fitness for the population.*11

\section{COMPARISON WITH POPULATION FITNESS NORMS}

National fitness normative data do not exist, nor have studies of fitness been performed in recent years on similar populations in Britain. Such data do exist, however, for comparable populations in Scandinavia and Canada as well as for factory workers in other countries.
One consideration must be kept at the forefront of $\overline{\bar{Q}}$ all such references to "normal" values-namely, that 3 normality does not necessary indicate a satisfactory $\frac{\mathbb{Q}}{2}$ condition but is merely an expression of the status $\overrightarrow{\vec{F}}$

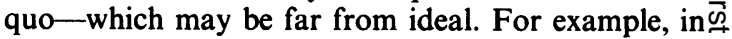
some tabulated values for fitness classification, cate- $\bar{C}$ gories may typically be labelled as "low, fair, average, good, and high." The two lower and upper categories $\frac{\bar{\rho}}{\triangle}$ are described qualitatively whereas the middle cate- $\stackrel{\mathbb{Q}}{\varrho}$ gory is not. Nevertheless, the implication is that average means "satisfactory." By the criteria so far dis- cussed, the average fitness of the factory population. cannot be described as satisfactory.

Two examples are given of fitness classification, $\stackrel{\omega}{\circ}$ one from Scandinavia ${ }^{31}$ (table $3 \mathrm{~A}$ ) and the other from the Canadian fitness survey of employees ${ }^{24}$ car- 3 ried out in 1977 as a pilot for the recent Canada fitness survey (table 4A).

It will be seen that the levels of fitness differ quite $\vec{\sim}$ substantially, the Scandinavian values, published in $\omega_{\omega}$ 1960 having been generated from many studies over응 several years, being higher than the Canadian ones.

The Canadian tables in their original form, as pub- $\vec{z}$ lished in 1978, are derived from a numerically large study of employees drawn from 52 different companies on a voluntary basis, not therefore representing norms for the population as a whole. They do, however, according to the report of the study "depict $\vec{O}_{\vec{O}}$ fair cross section of a working population which represents various occupational groups of white and blü collar workers."

As reproduced here the tables are in a modified

*The mean level of fitness appears to be extremely low for such $a \stackrel{2}{2}$ population, being reported as $140.1 \mathrm{~W}$ at a heart rate of 160 beats $/ \mathrm{min}$. With a mean age of 41.3 years and body weight of $\vec{F}$ $83.6 \mathrm{~kg}$ this converts, using Astrand's nomogram with age conversion, to a $\dot{V o}_{2} \max$ of about $25 \cdot 5 \mathrm{ml} / \mathrm{kg} / \mathrm{min}$.

Table 3A Scandinavian fitness standards $\dot{V}_{2} \max (\mathrm{ml} / \mathrm{kg} / \mathrm{min})$

\begin{tabular}{|c|c|c|c|c|c|}
\hline & \multicolumn{5}{|c|}{ Age (years) } \\
\hline & $20-29$ & $30-39$ & $40-49$ & $50-59$ & $60-69$ \\
\hline $\begin{array}{l}\text { Low } \\
\text { Fair } \\
\text { Average } \\
\text { Good } \\
\text { High }\end{array}$ & $\begin{aligned}< & 38 \\
& 39-43 \\
& 44-51 \\
& 52-56 \\
> & 57\end{aligned}$ & $\begin{aligned}<34 \\
35-39 \\
40-47 \\
48-51 \\
>52\end{aligned}$ & $\begin{aligned}< & 30 \\
& 31-35 \\
& 36-43 \\
& 44-47 \\
> & 48\end{aligned}$ & $\begin{aligned}< & 25 \\
& 26-31 \\
& 32-39 \\
& 40-43 \\
> & 44\end{aligned}$ & $\begin{aligned}<21 \\
22-26 \\
27-35 \\
\\
36-39 \\
>40\end{aligned}$ \\
\hline \multirow[t]{3}{*}{ Table 4A } & dian emp & standard & $\dot{V} o_{2} \max$ & & \\
\hline & \multicolumn{5}{|c|}{ Age (years) } \\
\hline & $20-29$ & $30-39$ & $40-49$ & $50-59$ & $60-65$ \\
\hline $\begin{array}{l}\text { Poor } \\
\text { Below minimum } \\
\text { Minimum } \\
\text { Good } \\
\text { Excellent }\end{array}$ & $\begin{aligned} &< 30 \\
& 31-35 \\
& 36-39 \\
& \\
& 40-44 \\
&>45\end{aligned}$ & $\begin{aligned} &< 27 \\
& 28-31 \\
& 32-35 \\
& 36-38 \\
&>39\end{aligned}$ & $\begin{aligned}<24 \\
25-27 \\
28-30 \\
31-33 \\
>34\end{aligned}$ & $\begin{aligned}<21 \\
22-24 \\
25-27 \\
28-31 \\
>32\end{aligned}$ & $\begin{aligned} &< 18 \\
& 19-21 \\
& 22-24 \\
& 25-28 \\
&>29\end{aligned}$ \\
\hline
\end{tabular}


form which, according to Bailey $e$ al $^{32}$ are suggested by Jette ${ }^{33}$ with all values reduced by $21 \%$ from the original ones to conform with predictions from a standard bicycle protocol. Originally the values were much closer to those in the Scandinavian tables. The higher values are reproduced in the operation manual for the Standardised Test of Fitness published in $1981 .^{34}$

Comparison with Canadian values is further complicated by the high "screening out" rate for the Canadian procedure, from $15 \%$ to $35 \%$ over the age range 35-59. This inevitably means that many subjects from the lower echelons of fitness are excluded from the population studied.

Mean fitness for 40-49 year olds and 50-59 year olds among the factory workers is, at $32 \mathrm{ml} / \mathrm{kg} / \mathrm{min}$ and $27 \mathrm{ml} / \mathrm{kg} / \mathrm{min}$ respectively, equivalent to the "good" value and "minimal" value in Jette's revised table. According to the Scandinavian table, however, they are only "fair."

\section{COMPARISON WITH OTHER STUDIES}

When values reported in other recent studies are examined (table 5) a fairly homogenous picture emerges for middle aged men, with fitness levels around $30 \mathrm{ml} / \mathrm{kg} / \mathrm{min}$ being an approximate mode for 40-49 year olds and slightly less for 50-59 year olds. Data reported by Åstrand ${ }^{31}$ and by Cuming $^{35}$ give rather higher fitness values for men in the sixth decade ("average" by the Scandinavian table) but, against this, other Scandinavian studies (Jonsson and Åstrand, ${ }^{36}$ Gyntelberg, ${ }^{37}$ and Wilhemson et al ${ }^{10}$ ) report values lower than or consistent with the general consensus. The Belgian epidemiological study reports a PWC 150 median value of $125 \mathrm{~W}$ (equivalent to a $\dot{V}_{2} \max$ of about $25.0 \mathrm{ml} / \mathrm{kg} / \mathrm{min}$ ). ${ }^{13}$

It is possible to select therefore either reassuring or disturbing comparisons for the fitness levels of the population of the present study. The probability is that these levels are not atypical of Western industrial society in general, and that fitness of middle aged men is low by the criteria of functional capacity and health protection in most affluent populations.

Physically active groups, whether by involvement in heavy manual work, now rare in Western society, or by participation in active leisure pursuits, show much higher values. The most impressive are those reported by Saltin for former athletes, both active and no longer active, ${ }^{39}$ while the American aircrew also show fitness to be activity related. ${ }^{40}$

Consideration of fitness of manual workers brings us back to an aspect of the first criterion discussedthat is, the adequacy of fitness for normal activity. Whereas exacting fitness demands are rarely made even on the manual workers at the factory studied, in industrial situations where heavy manual labour still exists the reported data show a surprising similarity from several different sources. Thus mean $\dot{V}_{2} \max$ for steelworkers from studies in Iran, ${ }^{41}$ Italy,,${ }^{42}$ and India $^{43}$ are similar, about $40 \mathrm{ml} / \mathrm{kg} / \mathrm{min}$. Wyndham, reporting the fitness demands of mineworking in South Africa, states that $45 \mathrm{ml} / \mathrm{kg} / \mathrm{min}$ is "the minimum required for the performance of hard work."44 Although perhaps it is entirely desirable that such a

Table 5 Fitness ( $\dot{V}_{2}$ max) of middle aged men from various studies

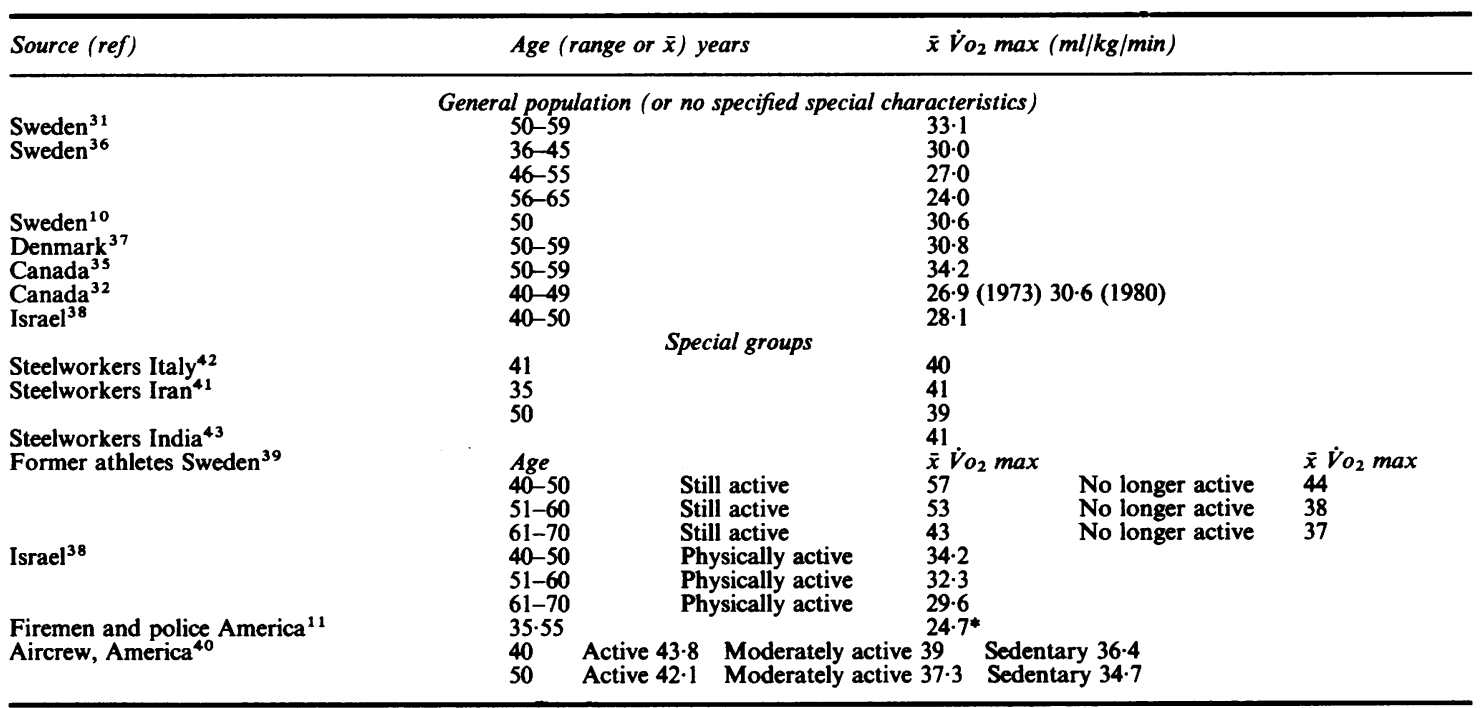

*140.1 Watts@160 beats/min heart rate, converted to estimated Vo $_{2}$ max using Åstrand's formula and age conversion factor. 
work capacity is no longer required for daily labour in civilised Western societies, the requirement for good health may still be of a similar order. Also, in a detailed consideration of the relation of physical work capacity to work rate and consequent relative fatigue, Astrand and Rodahl make the general observation that less fatigue will result at the end of an eight hour shift the greater the individual's work capacity is above the work requirement. ${ }^{45}$ They point out that objective fatigue will result from continuous work at $50 \%$ of $\dot{V}_{2} \max$ and recommends that $30-40 \%$ should not be exceeded as an average loading. In a society where it is no longer acceptable to think of leisure time as recovery from physical exhaustion at work these observations are of particular importance.

By all the criteria discussed, whether functional capacity, threshold of health protection, or comparison with fitness levels for other groups, particularly those of mixed activity, it appears that there are grounds for considering the fitness of the factory population as inadequate. This is despite a strong tradition of sporting provision and encouragement to participate, coupled with a vigorous health promotion programme at the factory, all of which circumstances are commonly less favourable in similar populations in Britain. The probability therefore is that the fitness of these workers is better rather than worse than average for middle aged British men.

\section{FITNESS-RELATION WITH OTHER VARIABLES Health risk factors}

The study of Peters et al of myocardial infarction in relation to fitness and established risk factors shows a strong dependency on the existence of other risk factors for a protective effect from relative fitness. ${ }^{11}$ The relation between exercise and other aspects of health enhancement is therefore of interest.

Among modifiable risk factors for cardiovascular disease, the most important appear to be hypertension, cigarette smoking, and hypercholesterolaemia. Blood lipids were not measured in the factory subjects, but relative obesity is strongly associated with adverse blood lipid profiles-that is, high serum cholesterol and low HDL-LDL ratios. Thus the measures of relative body weight and percentage body fat are of relevance to health risk.

\section{Hypertension and relative overweight}

High blood pressure is associated with relative overweight. In this study there is a low positive correlation between percentage body fat and both diastolic and systolic blood pressure $(r=0.18$ and 0.19 respectively). There is also an inverse relation of blood pressure to fitness $(r=-0.246$ for systolic pressure after controlling for age).
The usefulness of exercise in reducing body fat has $\overline{\bar{\alpha}}$ been well established in recent years as the $z$ importance of regular vigorous exertion to lipid $\stackrel{\mathbb{D}}{\circ}$ metabolism and the regulation of appetite have been more fully understood. ${ }^{46-48}$

Most recently attention has been focused on the $\overrightarrow{0}$ possibility that either indirectly through loss of body weight, or directly, increased regular exercise may be effective in the control of borderline or mild hypertension. Encouraging results have been obtained from several trials ${ }^{4950}$ and others are in progress.

The definition of mild hypertension used in a recent Medical Research Council (MRC) trial ${ }^{51}$ is phase V diastolic pressure of $90-109 \mathrm{~mm} \mathrm{Hg}$. Elsewhere values are referred to between 90 and $105 \mathrm{~mm} \mathrm{Hg} .{ }^{52}$

Rose has pointed out that whereas the individual risk from severe hypertension is much higher than $\vec{\omega}$ that from mild hypertension, the attributable deaths from the latter are numerically much larger because of the number of cases. ${ }^{53}$ It is estimated that some $25 \%$ of $35-64$ year olds in Britain have diastolic pressures between 90 and $109 \mathrm{~mm} \mathrm{Hg}$ whereas only $5 \%$ exceed $110 \mathrm{~mm} \mathrm{Hg}$. The management of mild hypertension is therefore of great importance.

Of the factory population tested, 329 subjects $(23.82 \%)$ had diastolic pressures in the range of $90-109 \mathrm{~mm}$, only a further $18(1 \cdot 3 \%)$ recording above $110 \mathrm{~mm} \mathrm{Hg}$, perhaps partly due to the prior screening $\vec{c}$ out of known extreme hypertensive subjects (not on because of risk involved in exercise testing but. because of the likely effect of medication on the te performance).

Of the 329 mild hypertensive subjects, the great majority were in the range $90-105 \mathrm{~mm} \mathrm{Hg}$, with 214 having diastolic pressures of $90-94 \mathrm{~mm} \mathrm{Hg}$.

In view of the conclusions from the recent MRC trial of drug treatment for mild hypertension, where death rates were the same in the treated groups as among those given a placebo, and the reduction in rates of stroke only prevented one event for 850 people treated a year (most of those treated suffering 3 chronic side effects "mostly but not all minor"), ${ }^{51}$ it ${ }^{\circ}$ would seem that most subjects with mild hypertension would have little to lose, and might benefit greatly, $ᄋ$ from increased physical activity rather than drug treatment. This would especially apply to the 214 men 의 last referred to, and probably to many of the men in $\square$ the sub-mild hypertension group approaching $90 \mathrm{~mm} \mathrm{Hg}$. In one of the trials referred to resting diastolic blood pressure was reduced from $99 \mathrm{~mm} \mathrm{Hg}$ o to $88 \mathrm{~mm} \mathrm{Hg}$ over a four months period of physical $\mathrm{N}$ training. ${ }^{50}$ Of even greater importance perhaps was the substantial reduction in both systolic and diastolic pressure during exercise, thereby reducing the risk normally encountered by hypertensive subjects dur- $\frac{\bar{D}}{\Phi}$ ing unaccustomed exertion. The apparent paradox of $\stackrel{\mathscr{D}}{+}$ 
taking exercise to reduce the risk of exertion is disposed of by pointing out that the exercise should be taken up gradually and progressively.

\section{Smoking}

The importance of tobacco smoking as a major risk factor in cardiovascular disease, more lethal even than as a risk factor in lung cancer, has established smoking as the single most devastating influence on health in Western society, being responsible for about 325000 premature deaths a year in the United States. ${ }^{54}$ Nevertheless, it is an entirely modifiable risk, and with regard to cardiovascular disease, reversible, in that ex-smokers gradually reduce their susceptibility to disease, though not to the levels of life long non-smokers. ${ }^{55}$

A less publicised effect of smoking behaviour is that of "passive" smoking - that is, the subjection to concentrations of tobacco smoke of occupants of the same air space as the smoker. This has been shown to increase significantly the predisposition to angina pectoris in sufferers. ${ }^{56}$

The prevalence of smoking in the factory population is somewhat below that reported in GHS, ${ }^{23}$ the high percentage of ex-smokers apparently reflecting the success of positive health intervention in previous years by the factory medical department.

In comparison with Wilhelmson's study ${ }^{10}$ in which subjects who engaged in more physical activity at work were more likely to be smokers than nonsmokers, our data show the overall predominance of non-smokers to persist in all physically active groups, whether occupational or leisure time. Nevertheless, relatively more smokers are found among the occupationally active than among the leisure time active groups, and slightly more relatively than among the occupationally inactive (tables 6 and 7).

Only $34 \%$ of the factory population were current smokers, compared with $54 \%$ of the Swedish 50 year olds, but the two studies are separated by a period of several years during which attitudes to smoking and consequent participation have changed. Thus the largest group of all at the factory comprises exsmokers.

Despite the tendency of the physically active groups to include more non-smokers, and the association of physical activity with fitness, there is no significant relation between smoking and fitness over the entire population. In part this could be explained by the greater body weight of non-smokers, especially ex-smokers, the latter appearing to have encountered some difficulty in readjusting food intake to changing metabolic needs. ${ }^{57}$ Indeed, if the body mass index criteria for overweight and obesity are applied, then $53.6 \%$ of ex-smokers and $49 \cdot 2 \%$ of non-smokers are overweight or obese compared with $42 \%$ of smokers. The lack of significant relation between smoking and fitness, however, persists even when a non-weight related criterion (gross $\mathrm{Vo}_{2}$ max) is used.

Within the groups taking regular physical exercise the disinclination to smoke is clear. For example, cyclists are less likely to smoke than non-cyclists ( $21 \%$ as opposed to $36 \%$ ) and those who cycle several hours a week even less likely to smoke (as little as $12.5 \%)$. These differences are highly significant $(\mathrm{p}=$ 0.0001 and 0.0039 respectively). The same pattern

Table 6 Respondents' smoking habits analysed by occupational activity levels

\begin{tabular}{|c|c|c|c|}
\hline \multirow[b]{2}{*}{$\begin{array}{l}\text { Occupational } \\
\text { activity levels }\end{array}$} & \multirow[b]{2}{*}{$\begin{array}{l}\text { Current smokers } \\
\text { No }(\%)\end{array}$} & \multicolumn{2}{|c|}{ Current non-smokers } \\
\hline & & $\begin{array}{l}\text { Ex-regular } \\
\text { No }(\%)\end{array}$ & $\begin{array}{l}\text { Never or occasionally } \\
\text { No }(\%)\end{array}$ \\
\hline $\begin{array}{l}\text { Sedentary } \\
\text { Light work } \\
\text { Moderately heavy work } \\
\text { Heavy work }\end{array}$ & $\begin{array}{c}92(19 \cdot 2 \\
5(1 \cdot 0) \\
224(46 \cdot 9) \\
157(31 \cdot 8)\end{array}$ & $\begin{array}{c}110(21 \cdot 7) \\
10(2 \cdot 0) \\
241(47 \cdot 6) \\
145(28 \cdot 7)\end{array}$ & $\begin{array}{c}137(33 \cdot 7) \\
8(2 \cdot 0) \\
160(39 \cdot 4) \\
101(24 \cdot 9)\end{array}$ \\
\hline All & $478(100 \cdot 0)$ & $506(100 \cdot 0)$ & $406(100 \cdot 0)$ \\
\hline
\end{tabular}

Table 7 Respondents'smoking habits analysed by leisure time activity levels

\begin{tabular}{lccc}
\hline Leisure time & & Current non-smokers \\
\cline { 2 - 3 } & $\begin{array}{l}\text { Current smokers } \\
\text { No }(\%)\end{array}$ & $\begin{array}{l}\text { Ex-regular } \\
\text { No }(\%)\end{array}$ & $\begin{array}{c}\text { Never or occasionally } \\
\text { No }(\%)\end{array}$ \\
\hline Sedentary & $141(29 \cdot 7)$ & $102(20 \cdot 2)$ & $77(19 \cdot 1)$ \\
Not very active & $60(12 \cdot 6)$ & $43(8 \cdot 5)$ & $33(8 \cdot 2)$ \\
Moderately active & $244(51 \cdot 4)$ & $312(61 \cdot 9)$ & $235(58 \cdot 2)$ \\
Active & $30(6 \cdot 3)$ & $47(9 \cdot 3)$ & $59(14 \cdot 6)$ \\
All & $475(100)$ & $504(100)$ & $404(100)$ \\
\end{tabular}


emerges for "relatively strenuous activity" ( $p=$ 0.0001 for differences according to increasing amounts of reported activity).

The effect of smoking on cardiorespiratory fitness is difficult to assess partly because smoking is rare among trained, highly motivated subjects in whom the relevant parameters would be most reliably measured, and because such subjects are disinclined to smoke even for experimental purposes. Theoretically, the reduced oxygen transport due to the preferential affinity of haemoglobin for carbon monoxide should increase the cardiac output required for a given level of $\dot{\mathrm{V}}_{2}$ thus increasing heart rate, an effect demonstrated 40 years ago. ${ }^{58}$

Airway resistance has also been found to increase two to three fold within seconds of inhalation of cigarette smoke ${ }^{59}$ (a situation not confined to the smoker himself). These are principally acute effects, although a chronic effect was found also for airway resistance due to swelling of the mucous membranes. These acute effects would not be present in smokers who had desisted voluntarily in anticipation of the test occasion and of necessity during the preceding medical examination, and would therefore not have affected their performance of the fitness test.

In conclusion, the tendency for non-smoking to be associated with sports participation and other leisure time physical activity, but not with occupational physical activity, might suggest that where exertion is voluntary rather than imposed it selects individuals who are not disposed to smoke, or even acts as a direct disincentive. Alternatively, the whole difference may be explained by a combination of the effects of social class on participation in leisure activities and on awareness of health risks. It is to be hoped that tobacco company sponsorship of sport will not be allowed to continue to undermine the negative association between sports participation and smoking.

The association of low coronary risk factors in general with leisure activity as shown in the Oslo study of 15000 men $^{60}$ and the Irish study of a similar number, ${ }^{61}$ is supported by the findings of this study.

FITNESS AND PHYSICAL ACTIVITY DURING WORK AND LEISURE

The results show that at all ages participation in relatively strenuous physical activities during leisure is strongly related to fitness as measured by the exercise test. By contrast, activity levels at work bear no relation to fitness.

This pattern of relation of fitness to physical activity of leisure but not that of work is consistent with that found by Hickey et al, ${ }^{61}$ where only leisure activity appeared to affect coronary risk factors. The lack of reduction in risk for heavy occupational physical activity is interpreted as suggesting that the effect of
Tuxworth, Nevill, White, Jenkins $\stackrel{\text { c }}{\mathrm{C}}$

exercise per se may be in doubt. Rather, Hickey et al $\overline{\bar{\alpha}}$ propose that men who are physically active during $\frac{2}{\infty}$ leisure time may smoke less and eat more prudently ? for personality, psychological, or cultural reasons. $\overrightarrow{\vec{F}}$ While acknowledging the probability of such an influence, it is thought that a more likely explanation in the case of the factory population is the low level of $\frac{\bar{F}}{\bar{D}}$ occupational exertion even among manual workers, which resulted in no fitness differential between active $\varrho$ and inactive groups at work.

The Oslo study, a four year mortality follow up of 15000 men aged 40-49, found a lower incidence of fatal heart disease to be associated with both physical $\vec{\omega}$ activity during leisure and at work. ${ }^{60}$ Other risk factors, however, such as high serum cholesterol, raised systolic blood pressure, and cigarette smoking were associated negatively with leisure activity but posi- $\omega$ tively with activity at work. The physical activity of leisure score proved to be almost as good a predictor as the coronary risk score of mortality over the period $\omega_{\omega}$ of observation. In the Belgian study fitness is related $\mathrm{S}$ to, but only weakly affected by, physical activity of leisure and occupation. ${ }^{13}$

The lightest categories of leisure exertion-namely, estimates of time spent walking and participating in fairly light physical activity-did not appear to affect fitness in the factory population, but it must be borne in mind that such estimates are notoriously inaccus rate and that the sensitivity of the fitness test ma have been inadequate for the task of discriminating finely at low levels of fitness. There is some debate as to the positive health value of low levels of activity. Thus Morris established the threshold above which protection might be afforded as "vigorous exercise," 28 whereas Rose discerned a lower risk of cardiovascular disease the greater the distance walked to work, ${ }^{62}$ activity of an intensity not meeting Morris's criterion.

On the basis of self reported participation in more vigorous categories of physical exertion in leisure, active participants were fitter than less active or sedentary, and the small number of respondents in the age range 35-44 who claimed to take part in relatively exhausting sports were considerably fitter. Duration of such participation was also significantly related to fitness.

Cycling is positively related to fitness and the few men who cycled regularly were among the fittest subjects of all. It might appear logical to expect habitual cyclists to perform better than non-cyclists in a fitness test using a bicycle ergometer because of better technique resulting in greater efficiency. This, however, has been shown not to be the case in normal populations, energy expenditure at a given level of external work on a bicycle ergometer being relatively unaffected by familiarity with that mode of exercise. 
It must be recognised, however, that the cyclists may have felt reassured by being asked to perform a familiar exercise and that their heart rate response therefore contained little or no component due to apprehension. Nevertheless, differences in fitness in favour of cycling are large enough to survive the possible effect of such a caveat.

The contribution of cycling to fitness has been frequently promoted and has been shown in recent studies on school children and adults. ${ }^{6364}$ In the present study it has greatest effect on fitness of an; of the lifestyle variables. The order of the difference in fitness in favour of cyclists is equivalent to that enjoyed by being five years younger (cyclists in general) or up to 10 years younger (for regular cyclists).

The relatively small number of cyclists almost certainly reflects the hazardous conditions for cycling in the urban environment, especially inhibiting the use of the bicycle as a means of travel to work. During the interview questionnaire the negative response to the cycling question was frequently accompanied by the observation that "it would be very nice to cycle if it were less dangerous."

In identifying the importance of non-occupationally determined exertion it must be recognised that over $70 \%$ of the population did not participate in any relatively strenuous activity whatsoever, one third describing themselves as leading sedentary leisure lives. In addition, such participation as there was in leisure time physical activity was unevenly distributed. Thus significantly more such activity was reported by non-manual and skilled workers than by semiskilled and unskilled, as in the Oslo study. ${ }^{60}$ Cycling, however, showed the opposite trend with a significant bias in participation towards manual workers.

A further aspect of voluntary exertion, the disposition to run while stair-climbing if late for an appointment or to catch a bus, emerged as being significantly related to fitness. For an essentially low activity population this may be an important determinant of fitness, representing for many individuals peak physical activity. The tendency for people to be "exertion seeking" or "exertion avoiding" needs much closer examination as do the links between such behaviour and attitude to exercise.

\section{Attitudes to exercise}

Time constraints limited the amount of information obtained from each subject so that attitudes to exercise could not be ascertained with any great detail or sensitivity. Some points of interest, however, did emerge.

Opinions regarding the value of exercise to health and to the control of body weight, when compared with actual participation and status regarding fitness and percentage body fat, show some puzzling discrep- ancies between behaviour and attitude. Hence despite $95 \%$ of respondents believing that exercise is certainly or probably good for health only $28 \%$ took part in significant physical activity. Health education is fraught with the problem of disparity between knowledge or beliefs and behaviour. In this case the highly positive response suggests that the great majority of the factory workers either already believed or had been persuaded that exercise is of value to health, but the depth of their conviction was not yet sufficient to bring about a behavioural change. The task for the health professional in addition to consolidating the informed beliefs already instilled is to identify the obstacles that stand in the way of translating those beliefs into action. Further specific investigation is needed but some help may be obtained from published surveys ${ }^{6465}$ and from the Sports Council and Health Education Council.

Belief in the value of exercise for controlling body weight was somewhat less secure, $80 \%$ nevertheless responding positively. The distribution of body fat, in relation to belief in the value of exercise to reduce it, shows that there is a tendency for those who believe it to be of value to be the least fat but not significantly so.

Eating habits, in terms of limiting food intake generally, show that those who did not limit food intake had the least fat, the lightest body weight, and the lowest body mass index ( $p<0.005$ for all age groups). The greatest values for these variables, however, occurred among those who limited food intake occasionally rather than the habitually restrained. The specific selection for limitation of foods popularly regarded as fattening was associated with greater body weight, body fat, and body mass index. Whether this reflects these individuals' restricting their diet because of being overweight is uncertain.

\section{RECOMMENDATIONS}

This study shows low fitness levels by the criteria discussed - that is, functional capability, health protection, and comparison with other studies among middle aged male factory workers at an establishment where health promotion and provision of recreational facilities are well above average for Britain. Vigorous physical exertion forms a part of the lifestyle of only a majority of the population but where it does it is associated with improved fitness. Relative fitness is associated with improved health status through lower blood pressures and less body fat. Participation in strenuous physical activity in leisure appears to be the principal modifiable determinant of fitness together with the adoption of a positive exertion seeking attitude. Cycling is particularly beneficial and already appears to be an activity embraced by social classes less amenable to health education.

It would seem desirable to study means whereby 
participation in regular relatively strenuous exertion may be fostered and facilitated in such populations, particularly as there appears to be already a major consensus of acceptance of the value of exercise.

Provision of exercise facilities at work should take cognizance of contemporary social trends in participation in physical activity. Particular attention should be paid to selecting activities that make cardiorespiratory demand but, especially in the case of older, less fit individuals and groups, where the demand is easily adjusted to appropriate levels.

The role of the company medical adviser is crucial in expanding health knowledge into the practice of a healthy lifestyle. Not only will he or she need to be able to answer employees' questions about the value or possible hazards of exercise, but there may also be some individuals who request an appraisal of their fitness followed by advice on appropriate types, levels, and intensities of exercise. It is unfortunately not too evident that the training of doctors prepares them for this role. ${ }^{66}$ An understanding of the nature and degree of exercise required to achieve a beneficial effect will enable the medical adviser to ensure the optimum effectiveness of any "in house" exercise facilities or schemes, and their integration within a positive health promotion programme. Detailed guidelines are available from numerous publications. ${ }^{67-70}$

Not only do the provision of facilities and opportunities for exercise need careful consideration but also conditions and amenities of normal factory life. For example, cycling or even jogging to and from work would probably be a much more attractive and comfortable proposition if showers and changing rooms were available at the workplace. ${ }^{71}$ The conservation of effort that has so long been the quest of industrial ergonomists may not always be in the best interests of the health of the workforce, and work tasks and individual mobility during the working shift may benefit from a new appraisal without necessarily prejudicing efficiency. For example the value of stair climbing as imposed regular exertion has been shown, ${ }^{72}$ and the status conscious may be protected from it at their peril.

Low levels of fitness can be improved. The lower they are the more rapidly improvement will occur. Studies of training response in sedentary middle aged men show improvements generally of the order of more than $15 \%$ in 10 weeks with exercise sessions of the order of 20-30 minutes three times a week of a suitable type and intensity. The improvements in the fitness scores for middle aged Canadians (table 5) between 1973 and 1980 are attributed ${ }^{32}$ to the national increase in participation in physical activity during that period.

Improvements will occur not only in heart rate response to a given level of work and in $\mathrm{Vo}_{2}$ max but also in the ability to sustain work at a given submaximal level of $\dot{\mathrm{V}}_{2}$ because of the important biochemical changes occurring in skeletal muscle. Heart muscle volume has also been shown to increase over a relatively short period of training in previously sedentary adults. ${ }^{73}$

Additional benefits may include a reduction of body fat in overweight subjects often accompanied by reduced blood pressure and enhanced blood lipid profile. Improved subjective well being may provoke increased health consciousness and a positive attitude towards reducing other risk factors. Studies in pursuance of the effects of the Canadian Fitness project have identified positive behaviour towards the reduction of health risks, ${ }^{74}$ improved psychological and attitudinal changes, ${ }^{75}$ reduced medical care costs, reduced absenteeism, ${ }^{76}$ and improved work performance among those participating in employee fitness programmes. ${ }^{77}$

The second part of this study, to be completed in $1987-8$, will be directed to showing associations between morbidity and the physical fitness and activity of the population here described.

Many people have generously contributed their time and expertise to this study. We express our particular gratitude to the personnel of Cadbury-Schweppeso especially to the participants in the study, the medicas staff which temporarily included doctors from the general practitioners' training scheme at Selly Oak Hospital, and to Mrs Norma Perrins for her administrative contribution and continuing work with regard to the monitoring of morbidity. We also thank Miss Susan Brailsford and $\mathrm{Mr}$ Tim Allen for their unstinting technical and other help during the arduous measurement stage, as well as those who carried out the interviews, always with patience and good humour.

\section{References}

1 Fentem PH, Bassey EJ. The case for exercise. London: Sports Council, 1978. (Research working paper No 8.)

2 Anonymous. Physical activity and health: a documentation. Scand J Soc Med (suppl) 1982;29:5-269.

3 Hanninen O, Kukkonen K, Vuori I. Physical training in health promotion and medical care. Ann Clin Res 1982;14(suppl 34):5-172.

4 Sports Council, Medical Research Society, and Health Education Council. Exercise, health and medicine. London: Sports Council, 1984.

5 Leon AS, Blackburn H. Physical inactivity. In: Kaplan NM, Stamler J, eds. Prevention of coronary heart disease. Philadelphia: WB Saunders Co, 1983.

6 Young A. Exercise in the prevention of disease and diability. In: Gray M Fowler G, eds. Preventive medicine in general practice. Oxford: Oxford University Press, 1983.

7 Haskell WL. Cardiovascular benefits and risks of exercise: the scientific evidence. In: Stauss R, ed. Sports medicine. Philadelphia: WB Saunders Co, 1984.

8 Wood PD, Haskell WL, Blair SN, et al. Increased exercise level and plasma lipoprotein concentrations: a one-year, randomised, controlled study in sedentary, middle-aged men. Metabolism 1983;32:31-9. 
9 Hartung GH, Squires WG, Gotto AM. Effect of exercise training on plasma high-density lipoprotein cholesterol in coronary disease patients. Am Heart $J$ 1981;101:181-4.

10 Wilhelmsen L, Tibblin G, Aurell M, Bjure J, Ekstrom-Jodal B, Grimby G Physical activity, physical fitness and risk of myocardial infarction. Adv Cardiol 1976;18:217-30.

11 Peters RK, Cody LD, Bischoff DP, Bernstein L, Pike MC. Physical fitness and subsequent myocardial infarction in healthy workers. JAMA 1983:249:3052-6.

12 Sobolski J, De Backer G, Degre S, Kornitzer M, Denolin H. Physical activity, physical fitness and cardiovascular diseases: design of a prospective epidemiologic study. Cardiology 1981;61:38-51.

13 De Backer G, Kornitzer M, Sobolski J, et al. Physical activity and physical fitness levels of Belgian males aged 40-55 years. Cardiology 1981;67:110-28.

14 McHenry PL. Risks of graded exercise testing. Am J Cardiol 1977;39:935-42.

15 Committee on Exercise. Exercise testng and training of apparently healthy individuals: a handbook for physicians. New York: American Heart Association, 1972.

16 Wahlund H. Determination of the physical working capacity. Acta Med Scand 1948;suppl 215.

17 Astrand 1. Aerobic work capacity in men and women with special reference to age. Acta Physiol Scand 1960;49(suppl 169):1-92.

18 Åstrand 1. The Minnesota code for ECG classification. Adaptions to CR leads and modification of the code for ECGs recorded during and after exercise. Acta Med Scand 1967;suppl 481.

19 Tuxworth W. Testing of cardiorespiratory performance. In: Eurofit, provisional manual. Strasbourg: Council of Europe, 1983.

20 Lange Anderson K, Shephard RJ, Wendin H, Varnauskas E, Masimi R. Fundamentals of exercise testing. Geneva: World Health Organisation, 1971.

21 Durnin JV, Womersley J. Body fat assessed from total body density and its estimation from skinfold thickness: measurements on 481 men and women aged from 16 to 72 years. Br $J$ Nutr 1974;32:77-85.

22 Bray GA. Obesity in America. Washington: US Government Printing Office. 1979. (DHEW publication No (NIH) 79-359.)

23 Office of Population Censuses and Surveys. General household survey. Cigarette smoking 1972-82. London: Government Statistical Service, 1983. (GHS 83/3.)

24 Jette $M$. The standardised test of fitness in occupational health: a pilot project. Can J Public Health 1978;69:431-8.

25 Royal College of Physicians. Obesity. J Coll Physicians Lond 1983;17:5-65

26 van der Walt WH, Wyndham $\mathrm{CH}$. An equation for prediction of energy expenditure of walking and running. J Appl Physiol 1973;5:559-63.

27 Paffenbarger RS, Hale W. Work activity and coronary heart mortality. $N$ Engl J Med 1975;292:545-50.

28 Morris JN, Chave SPW, Adam C, Sirey C, Epstein L, Sheehan DJ. Vigorous exercise in leisure-time and the incidence of coronary heart disease. Lancet 1973;i:333-9.

29 Passmore R, Durnin JVGA. Human energy expenditure. Physiol Rev 1955;35:801-40.

30 Paffenbarger RS, Hyde RT, Wing AL, Steinmetz $\mathrm{CH}$. A natural history of athleticism and cardiovascular health. JAMA 1984;252:491-5.

31 Astrand P-O. Physical performance as a function of age. JAMA 1968;205:105-11.

32 Bailey DA, Mirwald RL, Faulkner RA, Fairbairn R, Owen W. Cardiorespiratory fitness in Canada: a current view. CAPHER Journal 1982;Nov-Dec:2-8.

33 Jetté M. A comparison between predicted Voo max from the Astrand procedure and the Canada home fitness test. Can J Appl Sports Sci 1979;4:3214-8

34 Jetté M. Standardised test of finess, operations manual. 2nd ed. Ottawa: Fitness and Amateur Sport, 1981

35 Cumming GR. Evaluation of the Canadian home fitness test in middle-aged men. Can Med Assoc J 1977;117:346-53.

36 Jonsson BG, Astrand I. Physical work capacity in men and women aged 18 to 65. Scand J Soc Med 1979;7:131-42.

37 Gyntelberg F. Physical fitness and coronary heart disease in Copenhagen men aged 40-59. Danish Med Bull 1974;21:49-57.

38 Shoenfeld J, Shapiro J, Hanne N, Drory J, Kellermann J. Aerobic work capacity in sedentary men and active athletes in Israel. Isr J Med Sci 1977:13:240-4

39 Saltin B, Grimby J. Physiological analysis of middle aged and old former athletes. Circulation 1968;38:1104-15.

40 Wolthius RA. Froelicher VF, Fischer J, Triebwasser JH. The response of healthy men to treadmill exercise. Circulation 1977;55:153-7.

41 Shahnawaz H, Tuxworth W. The physical working capacity of Iranian steelworkers. Ergonomics 1978;21:63-71.

42 Cuttica F, Di-Prampero PE. Maximal aerobic and anaerobic power in a group of workers in heavy industry. Securitas 1970;55:205-13. (In Italian.)

43 Saha PN. Physiological evaluation of the job of doorman of the coke batteries of a steel plant. Bombay: Industrial Physiological Section, Central Labour
Institute, 1969:22 (DD).

44 Wyndham $\mathrm{CH}$. Measurement of the maximum oxygen intake of various South African Bantu groups. In: Weiner JS, Collins KJ, eds. Human adaptability. London: Taylor and Francis, 1977:250-1.

45 Åstrand P-O, Rodahl K. Textbook of work physiology. New York: McGraw Hill, 1977:291-329, 449-80.

46 Bjorntorp P. Physical training in the treatment of obesity. Int $J$ Obes 1978:2:149-56.

47 Gwinup G. Effects of exercise alone on the weight of obese women. Arch Intern Med 1975;135:676-80.

48 Kukkonen K, Rauraman R, Siitonen O, Hanninen O. Physical training of obese middle-aged persons. Ann Clin Res 1982;14(suppl 34):80-5.

49 Fagard R. Habitual physical activity, training and blood pressure in normoand hypertension. Int J Sports Med 1985;6:57-67.

50 Kukkonen K. Rauraman R, Voutilainen E, Lansimes E. Physical training of men with borderline hypertension. Ann Clin Res 1982;14(suppl 34): 139-45.

51 Medical Research Council Working Party. MRC trial of mild hypertension: principal results. $\mathrm{Br}$ Med J 1985;291:97-104.

52 WHO International Society of Hypertension: Hypertension Committee. Trials of the treatment of mild hypertension: an interim analysis. Lancet 1982;i:149-56.

53 Rose G. Strategy of prevention: lessons for cardiovascular disease. Br Med J $1981 ; 282: 1847-51$

54 Aronow WS, Kaplan NM. Smoking. In: Kaplan NM, Stamler J, eds. Prevention of coronary heart disease. Philadelphia: WB Saunders Co, 1983.

55 Doll R, Peto R. Mortality in relation to smoking. 20 years observations on male British doctors. Br Med J 1976;ii:1525-36.

56 Aronow WS. Effect of passive smoking on angina pectoris. $N$ Engl J Med 1978;299:21-4.

57 Blitzer PH, Rimm AA, Geiffer EE. The effect of cessation of smoking on body weight in $\mathbf{5 7 0 3 2}$ women: cross-sectional and longitudinal analysis. J Chronic Dis 1977;39:415-29.

58 Jaurup A. Muido L. On acute effects of cigarette smoking on oxygen consumption, pulse rate, breathing rate and blood pressure in working organisms. Acta Physiol Scand 1946;11:48-61.

59 Da Silva AMT, Hamosh P. Effect of smoking a single cigarette on the "small airways." J Appl Physiol 1973;34:361-5.

60 Holme I, Helgeland A, Hjermann I, Leren P, Lund-Larsen PG. Physical activity at work and at leisure in relation to coronary risk factors and social class. Acta Med Scand 1981;209:277-83.

61 Hickey N, Mucahy R, Bourke GJ, Graham I, Wilson-Davis K. Study of coronary risk factors related to physical activity in 15171 men. $\mathrm{Br} \mathrm{Med} \mathrm{J}$ 1975; iii:507-9.

62 Rose G. Physical activity and coronary heart disease. Proceedings of the Royal Society of Medicine 1969;62:1183-7.

63 Hudson C. Fitness, fatness and funtime of schoolgirls. Birmingham: Birmingham University, 1985. (MA thesis.)

64 Canada fitness survey. Fitness and lifestyle in Canada. Ottawa: Government of Canada, 1983

65 Owen N, Lee C. Why people do and do not exercise. South Australia: Department of Recreation and Sport, 1984.

66 Young A. Gray JAM. Ennis JR. Exercise medicine, the knowledge and beliefs of final year medical students in the United Kingdom. Medical Education 1983;17:369-73

67 American College of Sports Medicine. Guidelines for graded exercise testing and exercise prescription. 2nd ed. Philadelphia: Lea and Febiger, 1980.

68 Fentem PH, Bassey J. $50+$ advice to leaders. London: Sports Council, 1983.

69 American Heart Association Committee on Exercise. Exercise testing and training of individuals with heart disease, or at high risk for its development. A handbook for physicians. New York: American Heart Association, 1975.

70 Fentem PH. The physiology of exercise and training. Update 1984;1 Nov, 793-800.

71 Muir Gray JA, Young A, Ennis JR. Promotion of exercise at work. Br Med $J$ 1983;286:1958-9.

72 Fardy PS, Ilmannen J. Evaluating the effects and feasibility of men at work stairclimbing intervention programme for men. Med Sci Sports Exerc 1975;7:91-3.

73 Shapiro LM, Smith RG. Effect of training on left ventricular structure and function; an echocardiographic study. Br Heart J 1983;50:534-9.

74 Shephard RJ, Corey P, Cox M. Health hazard appraisal--the influence of an employee fitness program. Can J Public Health 1982:73:183-7.

75 Rhodes EC, Dunwoody D. Physiological and attitudinal changes in those involved in an employee fitness programme. Can $J$ Public Health 1980;71:331-6.

76 Donaghue $S$. The correlation between physical fitness, absenteeism and work performance. Can J Public Health 1977;68:201-3

77 Shephard RJ, Corey P, Renzland P, Cox M. Influence of an employee fitness and lifestyle modification programme upon medical care costs. Can J Public Health 1982:73:259-63. 